\title{
Disappearing gradually and unconsciously in rural China: Research on the sunken courtyard and the reasons for change in Shanxian County, Henan Province
}

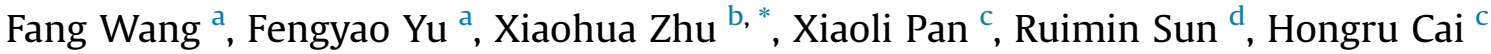 \\ a Sino-German Joint Laboratory on Urbanizaiton and Locality Research, College of Architecture and Landscape Architecture, Peking University, Beijing, \\ 100871, PR China \\ ${ }^{\mathrm{b}}$ Institute of Geographic Sciences and Natural Resources Research, Chinese Academy of Sciences, Beijing, 100871, PR China \\ ' College of Urban and Environmental Sciences, Peking University, Beijing, 100871, PR China \\ ${ }^{\mathrm{d}}$ School of Urban Planning and Design, Peking University, Shenzhen, 518055, PR China
}

\section{A R T I C L E I N F O}

\section{Article history:}

Received 31 October 2015

Received in revised form

4 May 2016

Accepted 6 May 2016

Available online 6 July 2016

\section{Keywords:}

Sunken courtyard

Chinese traditional dwelling

Rural heritage change

Heritage management

Rural policy

\begin{abstract}
A B S T R A C T
China's rural areas have entered an important period of modernization, experiencing the rapid transformation from traditional rural society to modern urban society. In this context, since the 1980s, the rural traditional dwellings with unique local characteristics and ecological advantages encounter an enormous threat. The rapid demolition of famous heritage sites and landscapes easily garners the public's attention, but traditional dwellings in rural areas are gradually disappearing as part of the residents' long-term daily practices. The cave dwelling, "sunken courtyard" (known as "di keng yuan" in Mandarin), is an appropriate subject for interpreting this type of change and cultural transformation. The sunken courtyards are primarily distributed throughout central China, Henan Province, Shanxian County; their unique architectural design method show the characteristics of the Loess Plateau culture. This study adopts qualitative research methods, selecting five study cases in Shanxian County, to discuss the changes in the traditional sunken courtyard and to explore the reasons behind these changes. Based on the literature and preliminary investigation, a formal interview was conducted. The results indicate the causes of the changes in terms of decoration, custom, family structure and policy. Additionally, the key conclusion is that the rural land use policy, the limitations of the sunken courtyard itself, the change in residents' ideas and the lack of proper management are the major reasons for this heritage change phenomenon. This study proffers a method regarding the protection of traditional dwellings to attract attention to the disappearing dwellings and to provide a scientific planning method for them.
\end{abstract}

(c) 2016 Elsevier Ltd. All rights reserved.

\section{Introduction}

China's rural areas have entered an important period of modernization, experiencing a rapid transformation from traditional rural society to modern urban society. Rural China is facing significant out-migration, as some Western countries did after the Second World War (Long and Woods, 2011). Rural development faces the challenges of population emigration, employment, land use, resource consumption and environmental governance (Liu and

\footnotetext{
* Corresponding author.

E-mail addresses: wfphd@pku.edu.cn (F. Wang), fengyao_yu@126.com (F. Yu), zhuxhigsnrr@163.com (X.ZZhu),806656571@qq.com (X.Pan), 1023725307@qq. com (R. Sun), caihr.pku@gmail.com (H. Cai).
}

Zhou, 2015). Following the reforms and opening-up of 1978, socioeconomic development and improvement in rural living standards have caused rural residents to abandon traditional housing in village cores for new housing on city and village fringes (Long et al., 2012). In this context, a variety of traditional cultural landscapes have been damaged or have disappeared. Particularly, traditional dwellings with important local characteristics and ecological advantages encounter an enormous threat.

The evolution of rural dwelling patterns, styles and appearances can reflect changes in farmers' production and living styles (Fang and Liu, 2009). Traditional houses are the carriers of historical change and traditional culture. Focusing on changes in traditional houses over time can provide ideas for how to protect cultural heritage and enable the sustainable development of traditional 
architectural culture. The sunken courtyard, which local people know as "di keng yuan" in Mandarin, is a specific type of cave dwelling. The spatial forms of Chinese cave dwellings can be divided into three categories: cliffside-type, detached-type and sunken-courtyard-type. The sunken-courtyard-type is beneath the land surface and usually involves a large square or rectangular excavated pit with cave dwelling units dug around the perimeter. These dwellings are primarily distributed throughout central China, especially in Shanxian County, Henan Province. This type of heritage cave dwelling is an appropriate subject for interpreting cultural transformation in the context of rural restructuring. The sunken courtyard was developed from cave dwellings in the primitive period; its unique architectural design method shows the characteristics of the Loess Plateau culture. It was adapted to the production conditions of the past agricultural society. In the last ten years, the overall level of urbanization in Henan Province has increased dramatically (Chen and Liu, 2014). The number of sunken courtyards has decreased by $10 \%$ per year since 1978 , and the reduction continues to increase in speed (Ma, 2010). The protection, renovation and development of sunken courtyards has become a key topic in Chinese vernacular architecture research.

The rapid demolition of famous heritage sites and landscapes in the pursuit of commercial interests easily garners the public's attention, but traditional dwellings in rural areas are gradually being replaced by modern-style houses as part of the residents' long-term daily practices. In these places, the people who still live in the rural environment actually use these heritages sites. However, similar to boiling a frog in cold water that is slowly heated, the disappearance of rural traditional dwellings is occurring gradually and unconsciously, so it has evaded notice. By the time people realize that changes are taking place, it may be too late to protect these heritages because irreversible damage will have already occurred. In this process, the colorful heritage of traditional dwellings in rural China has been unknowingly disregarded, along with changes in traditional rural customs and the loss of related construction skills. The features and characteristics of rural environment have gradually become monotonous and mediocre. Current international research mainly focuses on the energy conservation, heritage value and historical significance of cave dwellings; there is great research potential from the perspective of local residents under the context of urbanization and rural restructuring. Local residents are the creators, users and protectors of traditional dwellings; they have the closest relationship with heritages, and have been with them for the longest time. The residents master traditional building skills and preserve shared memories. These memories are agrestic and local, different from national memories in that they can become symbols of the local area, so they deserve special attention when facing the cultural assimilation that accompanies globalization. Taking into account the perspective of local residents, researchers can provide a deep understanding of the unique characteristics of heritage sites, give an account of how folk customs are forgotten or preserved, and examine the reasons for these changes. In addition to understanding heritage sites from the perspective of the authorities, the perspective of local residents offers an important supplement. This study adopts qualitative, in-depth interview methods to examine changes in the prevalence of sunken courtyards, using this type of building in Shanxian County, Henan Province as an example. The results reveal the causes of changes in heritage architecture in relation to architectural form, decoration, custom, policy and family structure. This study suggests methods for protecting traditional dwellings, for drawing public attention to disappearing dwellings, and for providing scientific planning methods to implement these goals.

\section{Traditional rural dwellings and the Chinese context}

\subsection{Value and plight of traditional dwellings}

The traditional dwellings are indigenous and originate from folk society; they are the local architectural forms that have great historical and cultural value and ethnic characteristics (Lu, 2007). The houses are distributed in vast countrysides and towns; they are not designed by professional architects but are built by local villagers with vernacular materials and traditional skills. The dwelling models were formed in agricultural society and remain until today (Shan, 2004). Certain traditional houses are where culture and tradition collides with the local daily life; the respective dwellings have close relationship with the local environmental characteristics (GhaffarianHoseini et al., 2014). They not only have strong aesthetic characteristics, but also partly adapt to local climatic conditions; the ancient construction skills can provide low energy solutions for the modern world (Gou et al., 2015). It could be concluded that traditional dwellings are the integrated embodiment of ecological, cultural and functional values.

Rural areas are in a more advantageous position to preserve and sustain their built environment including traditional heritage because of their static demographic structure and means of production (Günçe et al., 2008). However, in the process of modernization, certain rural traditional houses are gradually encountering the plight of development and function as farmers' living conditions have improved a lot. Certain traditional activities related to pre-modern rural life may no longer be obvious, so that houses are required to accommodate new activities (Chuapram et al., 2012). Many studies show the limitations of traditional dwellings in adopting themselves to modern rural life. Their design and techniques cannot always meet the modern living style (Bodach et al., 2014). Some basic modern living facilities like health space, bathroom, lighting, ventilation and kitchen insulation are many features that appear unsuitable in the traditional architecture, and these contradictions are the important reason that the local people spontaneously abandon or retrofit them (Dong and Jin, 2013). Moreover, although the cultural and social values are admitted by local people, their limitations are also widely noticed. The study of Iranian traditional loggias not only shows that the spaces are created to serve residents' social, cultural and aesthetical requirements, but also the negative aspects that they are perceived to be inconvenient, uneconomic and often impractical (Foruzanmehr, 2015).

The five types of changes in landscape elements in villages are add, continue, customize, transform and repair (Fatimah, 2015). The changes of traditional dwellings under these dilemmas are affected by a series of comprehensive factors. Economy plays an important role and is the root of all of these changes (Al-Naim and Mahmud, 2007); social and cultural changes also result in the changes of traditional dwellings (Chuapram et al., 2012). Local residents' minds are changing as new industries come into their daily life. For instance, with the development of tourism, the capital-oriented value system replaces the traditional personal relationship and service concept, leading to the transformation of traditional houses (Hanan, 2012). Additionally, modern technology in building materials and construction techniques play a very strong role in the transformation of the traditional houses (Al-Naim, 1998; Cited in Al-Naim and Mahmud, 2007: 426). For example, with wide social acceptability and economic sustainability factors, the contemporary concrete balustrade appeared in the Nigerian vernacular ar- 
chitecture (Osasona et al., 2010). The rural dwellings studies in Venezuela also indicate that modern, concrete houses are a major pursuit by local people, while it cannot adapt to the local tropical humid climate (Rakowski, 1995).

\subsection{Changes in Chinese traditional dwellings in the context of rural restructuring}

Rural agricultural society has always held an important position in China. With increasing development and the propulsion of urbanization, the economic, social, and cultural characteristics of traditional settlements in rural areas are gradually transforming (Zhang, 1998). One aspect of rural restructuring and development can be observed in changes to the social and cultural landscapes (Wang et al., 2010). In rural areas, local traditional living and production customs, dwellings, and village patterns often have distinctive geographical and ethnic characteristics (Zhou and Zhong, 2015). However, with the wave of new rural construction, the large-scale demolition and renovation of rural dwellings and centralized planning of new rural residential areas have diminished the cultural distinctiveness of rural architecture (She, 2015). The phenomenon of "hollow village" in China, resulting from the dualtrack structure of rural and urban socio-economic development, created vacant and abandoned housing land in many rural communities (Long, 2014). Traditional dwellings are important rural geographical elements, therefore their plight and the changes they are undergoing have caused widespread concern among scholars. Current research on this issue primarily adopts the approach of analyzing change factors and then exploring the reasons behind them.

Regarding change factors, researches focus both on a particular single factor and multiple factors such as the location, spatial forms, architectural structure, material, detailed characteristics and the cultural evolution process ( $\mathrm{Pi}, 2008$ ). For instance, a study has been conducted on the changes of traditional dwellings, including the courtyard structure, building facade and Chinese fengshui elements (Wang and Zhou, 2011). In recent years, scholars have focused more on the social factors in the changes of traditional dwellings. Researchers have explored dwellers' responses to the changes in the social economic environment and the residents' lifestyles. Factors such as family ethics, relationships, daily life style, social security status and the influence of traditional Chinese traditional philosophy are all considered (Chen and He, 2010).

The studies on the causes of dwelling change show that traditional dwellings are influenced by a series of comprehensive factors including policy, economy, culture, climate and environmental conditions, as well as production and living styles. Research indicates that the changes in the traditional values, the improvement of villagers' economic levels, the radiation effect of massive media and the popularization of modern building materials are the main reasons that traditional dwellings have been abandoned or replaced (Kuang and Zeng, 2007). In addition, the decrease in local natural resources for building materials, the unconsciousness of local culture, the neglect of the administrative department, the declining numbers of traditional craftsmen and the limitation of the traditional dwellings, have all led to the changes in traditional dwellings in modern China (Li, 2012).

\subsection{Study of traditional cave dwellings}

Since 8000 B. C., during the late Paleolithic age, the 'cave' has been the primary form of residential housing. Cave dwellings have strong adaptability to the social, historical and mainly natural conditions (topography, geology and climatic) of the landscape where they are placed (Barbero-Barrera et al., 2014). Many studies show that cave dwellings provide environmental benefits. Certain cultures, such as those of China, Turkey and Tunisia, have successfully used subsurface construction as a natural means of tempering the living environment (Al-Temeemi and Harris, 2004). With new technology, the pit yard in Iran could help to keep the air cool and to reduce fossil energy usage (Saljoughinejad and Sharifabad, 2015). In the Western Desert, the sunken courtyard mitigates the hot, dry climate and reduces energy consumption (Hassan and Lee, 2014). Modern green engineering can learn from underground heritage dwellings, which can conserve energy, protect local aesthetics, and maintain a low level of impact on the landscape (Benardos et al., 2014). Meanwhile, a number of drawbacks are also present. The traditional cave houses in Crevillente (Spain) are more susceptible to a lack of ventilation, and they accumulate indoor radon (Piedecausa and Chinchón, 2015). Certain types of underground dwellings were built in response to conditions of poverty and misery, an association that causes the disappearance of this type of heritage dwelling (Moldovan et al., 2015). In contrast to common urbanization patterns, underground shelter communities have their own unique codes and customs (Erdem, 2008).

Loess deposition is one of the most typical landforms that reflect the natural, climatic and biological historical changes on the earth. The loess landforms located mainly in China are characterized by their broad coverage, great thickness and high degree of stratigraphic integrity (Guo et al., 2011). Under such geographical conditions, cave dwellings utilize loess as building materials to construct the surrounding and supporting system; these are excavated using manual labor in loessial areas to create residential space (Wang, 2012). Different names are provided to such types of cave dwellings. In this research, the study cases in Shanxian County are entirely sunken-courtyard-type cave dwellings.

With the development of rural society and the improvement of economic conditions, sunken courtyards are being buried and abandoned at an astonishing rate. Since the 1980s, indigenous residents have left their sunken courtyards one after another, and built one-story houses with brick and cement (Zhang, 2011). In Chinese rural areas, local villagers spontaneously construct these common modern residences with modern materials, mainly brick, concrete, timber and cement, creating residences that are quite different from traditional cave dwellings. Additionally, there are modern sanitary facilities inside the houses, in addition to air conditioning and heating. The layout and decoration of the houses are more suitable for modern living than those of traditional dwellings (Shi, 2011). Because sunken courtyards have a large area of floor space, in the mid-1990s, villagers were encouraged to build new one-story houses while burying their existing caves; thus, the whole village was moved to aboveground from underground (Xu, 2009). Statistics show that, in the early 1980 s, $7.8 \%$ of residents in sunken courtyards moved out; the percentage grew to $22 \%$ during 1990-2001, and during 2001-2010, approximately 54\% of the local residences moved out (Qin, 2010). It could be concluded that the traditional sunken courtyards in this county have been disappearing gradually over the past 30 years.

In conclusion, the traditional dwellings heritage that formed during the long-term historical process, on the one hand, has its unique ecological, cultural and functional value. On the other hand, this heritage has difficulties in adapting to the modern social environment. Existing studies have involved multiple disciplinary perspectives such as architecture, ecology, economics, sociology, tourism and cultural studies. Case studies have mainly regarded a 
certain village in Shanxian County, among which Miaoshang Village is the most frequently selected. However, there is a lack of studies on the integrity and transition process of cave dwellings, addressing the entire county region. In this study we expand the scope of research to include five different representative villages within the whole of Shanxian County, exploring the transition process from the multiple perspectives of architecture, culture, family structure and rural policy. Therefore, this study offers a comprehensive investigation, using the expanded scope of the entire county. Additionally, it provides a systematic study of the characteristics of sunken courtyards during the gradual process of change, in addition to an account of the reasons for these changes occurring. This study hopes to contribute to the scientific planning, management, preservation and development of traditional dwellings heritage.

\section{Research design and investigation process}

\subsection{Study area}

The sunken courtyards described in the study are located primarily in Shanxian County, Sanmenxia City in western Henan Province (Fig. 1). The county is situated in the south of the middle reaches of the Yellow River, located in the eastern branches of the
Qinling Mountains. The landscape is mainly hilly, and the soil is of suitable viscosity for building. The region has a long history of building sunken courtyards, dating back at least 2000 years. This type of dwelling was created by local residents through long time of experience and possesses a high degree of adaptability to the geomorphic conditions.

Recently, studies on sunken courtyards in Shanxian County have continuously increased. Researchers have examined the form, space, function, material, technology, structure, custom and culture of sunken cave dwellings and evince suggestions for their preservation and development (Hou and Wang, 1999; Zuo et al., 2012); provided an explicit description of its formation, structure and architectural features, as well as the custom and folk literature (Yun, 2009); evaluated the ecological importance of sunken courtyards (Gao and Tian, 2013); and examined the formation, architectural characteristics, culture, environment, technology and reuse potential (Shang, 2011). Yang et al. (2012) documented the reclamation process of sunken courtyard land in Shanxian County and discovered that the owners had witnessed and contributed to the transformation of this traditional house; this would make the owners thoroughly eradicate the sunken courtyard culture.

This article selects the sunken courtyard in Henan Shanxian as the research sample for the following reasons:

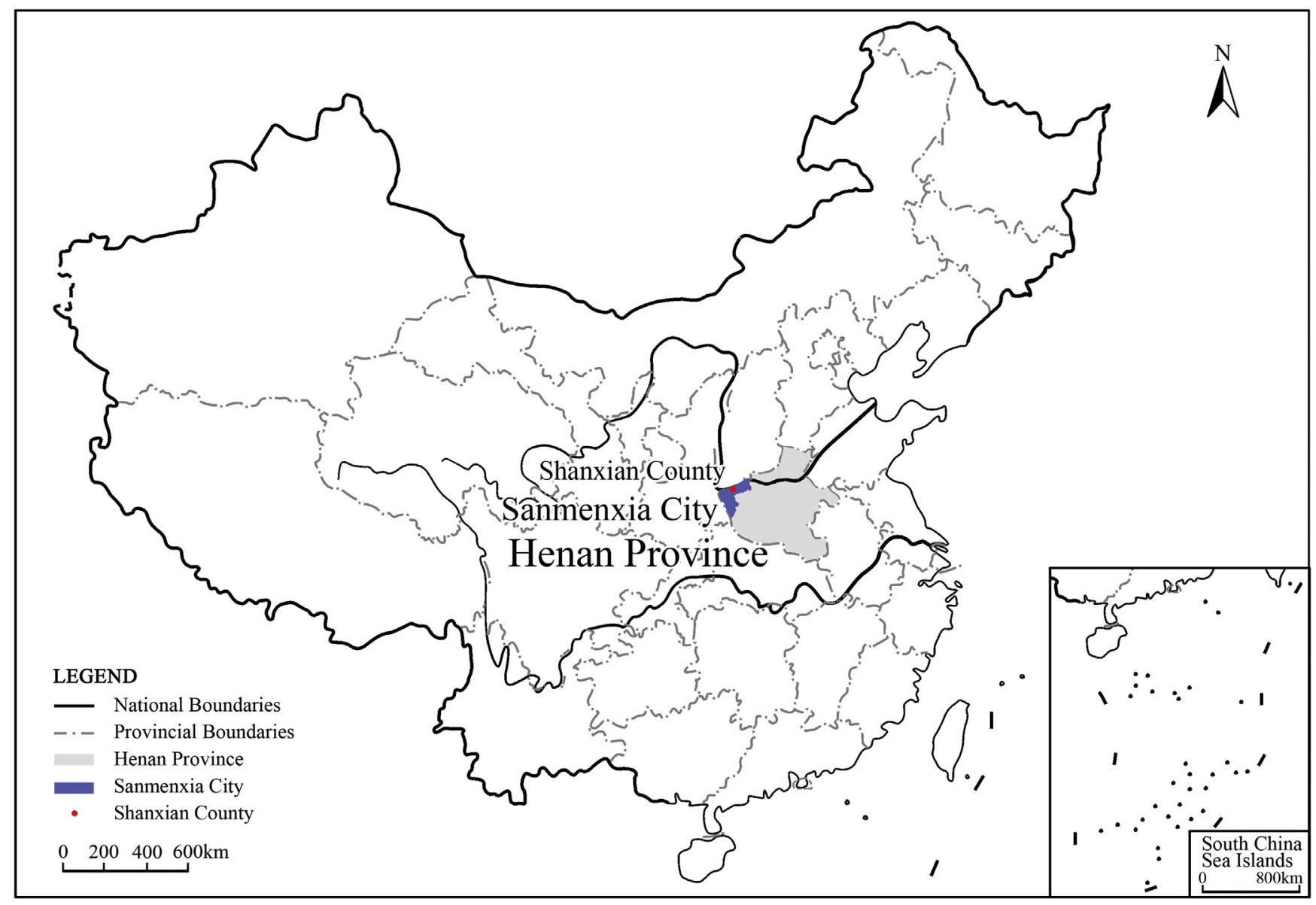

Fig. 1. Shanxian County, Sanmenxia City of Henan Province. (Source: Authors). 
1) Sunken courtyards have a long history in this region, which may date to the Yangshao Cultural period (BC5000-BC3000). The sunken courtyards here were built with native construction techniques and unique procedures. Its construction is scientifically sound; its appearance is beautiful, and the whole structure is energy efficient in addition to having a minimal carbon footprint. The entire building is the result of people's creativity and wisdom, accumulated over thousands of years. This type of residential building shows the close relationship between man and earth and is thus an important example of traditional dwellings in China.

2) Sunken courtyards in Shanxian County are representative of Chinese Loess culture; however, in the reform and opening-up process, their numbers have greatly decreased. This trend toward disappearing is indicative of the social upheaval taking place in China over the past 30 years.

3) People have begun to re-evaluate this type of traditional residence and the strong local attachments to it. Certain practices of renewal and regeneration have also occurred spontaneously. In 2007, all sunken courtyards in Shanxian County were added to the first batch entries on the Intangible Cultural Heritage List in China. By the end of 2012, Miaoshang Village was added to the first group of Traditional Villages in China by China's Ministry of Housing and Urban-Rural Development. In March 2013, Miaoshang Village was again recognized by the State Council, added to the seventh group of National Crucial Cultural Relics Protection Units. Under this condition of protection and renewal, the study of sunken courtyards and the dynamics of their protection in modern society will have broad significance.

To consider both typicality and integrity, this study selected five villages in Shanxian County as the research sites, which were chosen for the following reasons:

1) The selected villages are widely and evenly distributed. Zhaoyuan Village, Miaoshang Village, Qucun Village, Nangou
Village, Renmazhai Village are in the east, south, west, north and central part of Shanxian County, respectively (Fig. 2).

2) The sunken courtyards in these villages are very concentrated and have large total quantities (Fig. 3).

3) The villages have different characteristics. Sunken courtyards in these five villages are distinctive in quantity, quality, preservation level and cultural relic status; each one is representative of a different type (Table 1 ).

\subsection{Methods}

This study adopted the methods of literature review and indepth on-site investigation to obtain data in addition to the interviews that constitute its most important means of collecting information. In the research process, the method of maximized differences sampling was employed to create a sample group as large and diverse as possible, thus providing a comprehensive depiction of the evolution of sunken courtyards. In mid-March 2013, a pre-investigation was conducted among residents in the selected five case areas, focusing on topics related to the evolution of sunken courtyards. The investigation originated with the living conditions of residents in sunken courtyards, resulting in the generation of a table summarizing change factors in sunken courtyards (Table 2). Additionally, a final interview outline was designed on the basis of pre-investigation. Then, an inclusive semistructured interview investigation was conducted in April 2013 (Table 3). The interview was controlled and designed in structure, but it also encouraged the respondents to express their own questions and opinions. The research team interviewed 22 people and obtained 19 valid samples in total. With the respondents' agreement, their phone numbers were retained for further investigation. The interviews were all recorded and then converted into written materials, providing the basic qualitative research data in this paper.

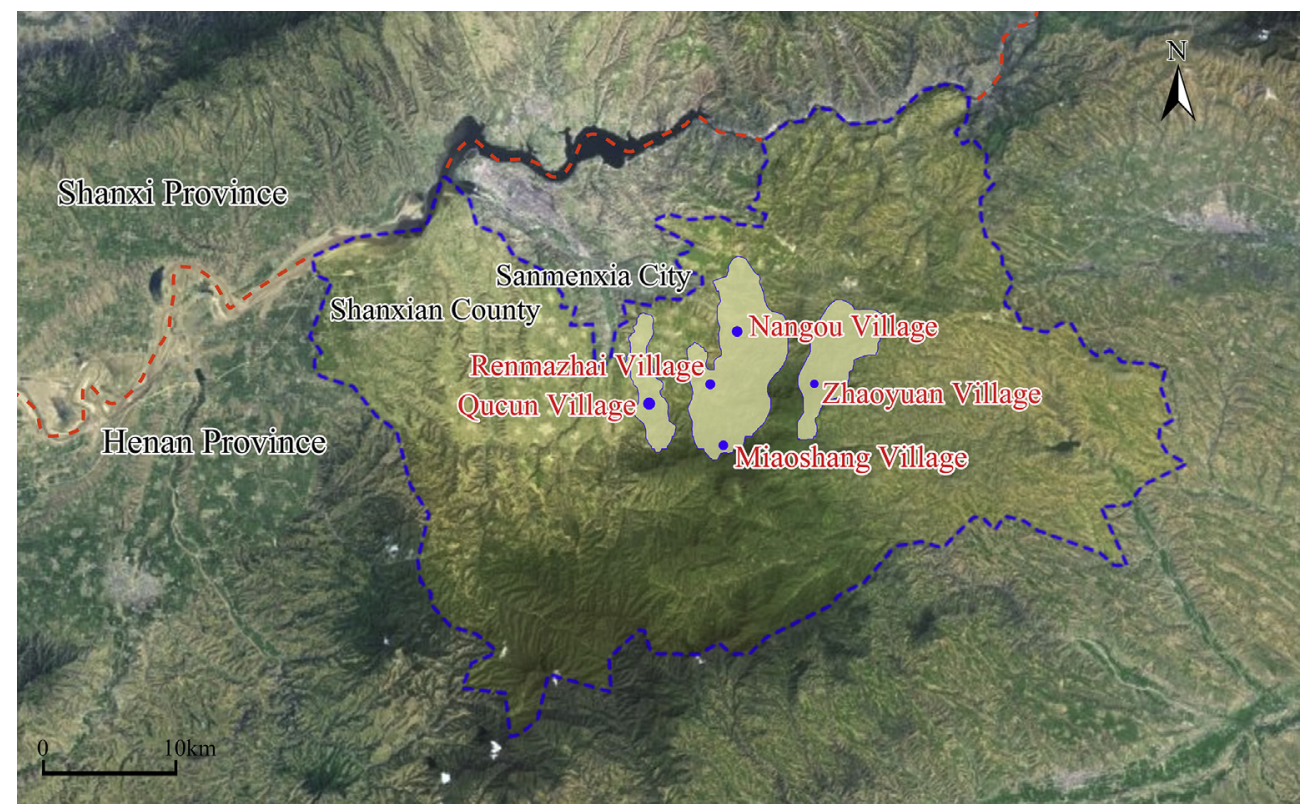

Fig. 2. The distribution area of the villages studied.

(Source: Basic map from Google Earth, modified by the authors) 

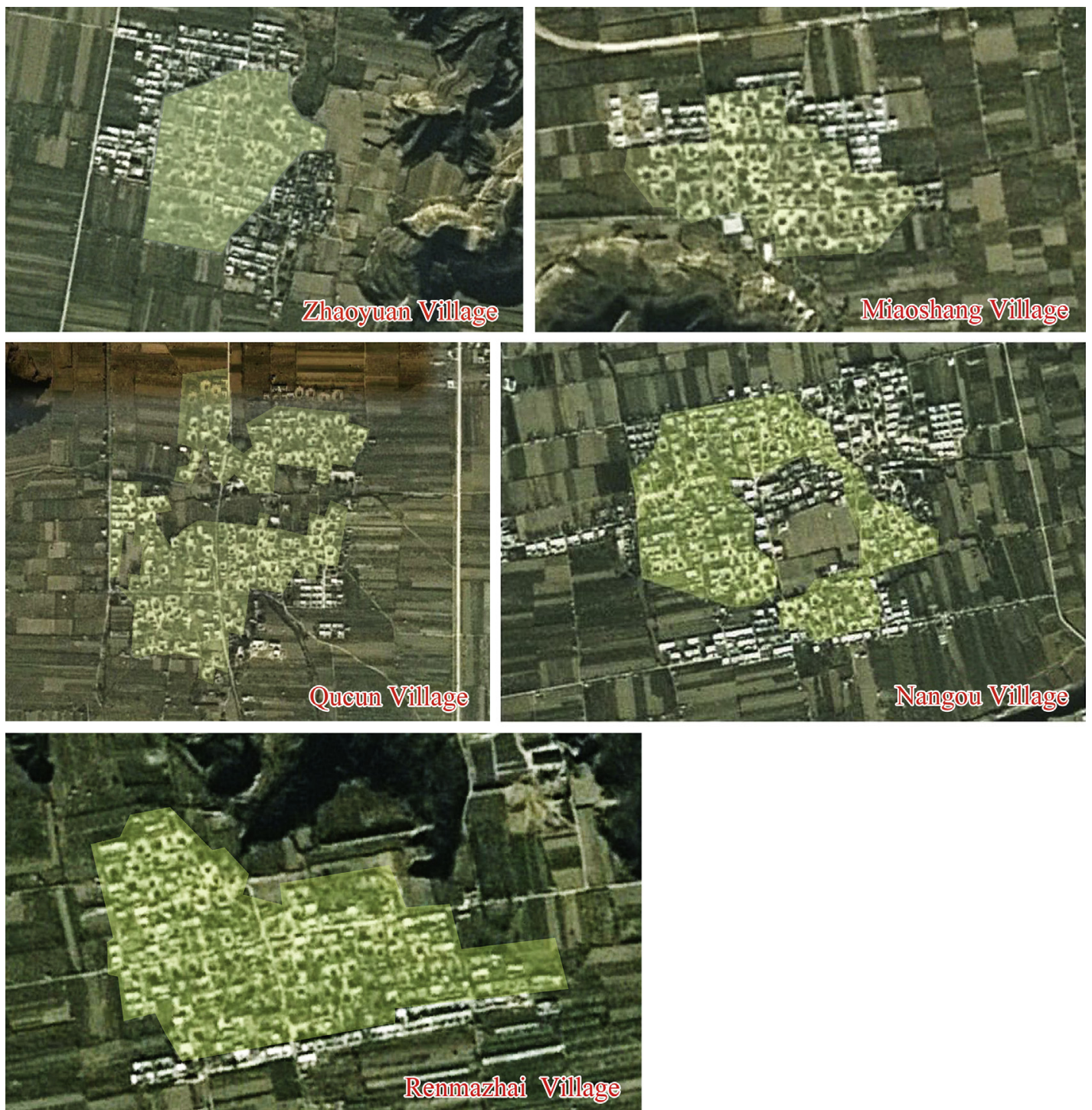

Fig. 3. The sunken courtyards are concentrated in the villages studied.

(Source: Basic map from Google Earth, modified by the authors)

Table 1

Basic situation of the sunken courtyards in each village.

\begin{tabular}{|c|c|c|c|c|c|c|}
\hline $\begin{array}{l}\text { Name of } \\
\text { the villages }\end{array}$ & Position & $\begin{array}{l}\text { Survival } \\
\text { status }\end{array}$ & Characteristics & $\begin{array}{l}\text { Existing } \\
\text { number } \\
\text { in } 1980\end{array}$ & $\begin{array}{l}\text { Existing } \\
\text { number }\end{array}$ & $\begin{array}{l}\text { Residential } \\
\text { number }\end{array}$ \\
\hline Zhaoyuan & In the east of the distribution area & Natural status & Endangered & More than 120 & 52 & 5 \\
\hline Miaoshang & In the north of the distribution area & Protected & Protected as cultural relics & More than 80 & 79 & 27 \\
\hline Qucun & In the west of the distribution area & Developed & Developed as tourists' resorts & More than 300 & 115 & 58 \\
\hline Nangou & In the north of the distribution area & Natural status & Paper-cut & 213 & 82 & 25 \\
\hline Renmazhai & In the middle of the distribution area & Natural status & Cheng-ni ink stone & More than 500 & 51 & 26 \\
\hline
\end{tabular}

(Source: The existing number and the residential number were provided by the Village Committee; other data were collected by the authors)

\section{Results}

Based on the data collected with methods outlined above, the researchers conducted an analysis using the two-level change factors established in the previous section. The analysis can be divided into two dimensions: the basic material dimension (including basic information and architectural decoration) and the folk cultural dimension, (i.e. customs).

\subsection{Basic information}

The quantity of sunken courtyards has changed a great deal, indicating the decline of these traditional dwellings, while area, residence type, unit number, plane layout and interior arrangement have changed little. This shows that the basic physical forms of sunken courtyard buildings could endure through time. 
Table 2

Change factors of sunken courtyards, Shanxian County.

\begin{tabular}{|c|c|c|c|}
\hline Level 1 & Level 2 & & \\
\hline \multirow[t]{2}{*}{ 1. Basic information } & 1. Quantity & 2. Area & 3. Residence type \\
\hline & 4. Unit number & 5. Plan layout & 6. Interior arrangement \\
\hline \multirow{5}{*}{$\begin{array}{l}\text { 2. Architectural } \\
\text { decoration }\end{array}$} & 7. Tunnel & 8. Archway & 9. Eaves gallery \\
\hline & 10. Cliff surface & 11. Horse-blocking wall & 12. Eave \\
\hline & 13. Cornice & 14. Broadside leading upward to the door & 15. Part beside the door \\
\hline & 16. Lower part & 17. Door and window & 18. Indoor floor \\
\hline & 19. Interior wall & & \\
\hline \multirow{5}{*}{$\begin{array}{l}\text { 3. Folk construction } \\
\text { customs }\end{array}$} & 20. Site investigation & 21. Orientation & 22. Create terrain \\
\hline & 23. Direction & 24. Final closure & 25. Visit the new yard \\
\hline & $\begin{array}{l}\text { 26. Keep the main cave } \\
\text { the largest }\end{array}$ & 27. Build the tian cave if there is no main cave & 28. The size of kang is seven's module \\
\hline & $\begin{array}{l}\text { 29. The size of the cave } \\
\text { is five's module }\end{array}$ & $\begin{array}{l}\text { 30. The doorway cannot be in opposition } \\
\text { to the road }\end{array}$ & 31. The doorway must bend inward \\
\hline & $\begin{array}{l}\text { 32. The doorway cannot be } \\
\text { in opposition to the door }\end{array}$ & 33. The "door of fortune " cannot be exposed & 34. Civilians cannot open the Zhongyi Door \\
\hline \multirow[t]{3}{*}{$\begin{array}{l}\text { 4. Production and } \\
\text { living customs }\end{array}$} & $\begin{array}{l}\text { 33. Worship gods to guard } \\
\text { against devils }\end{array}$ & 34. Worship Chinese toon & 35. Plant "auspicious" trees \\
\hline & $\begin{array}{l}\text { 36. Dry grain on the sunny } \\
\text { open ground }\end{array}$ & $\begin{array}{l}\text { 37. Drip grain through the "horse-eye hole" } \\
\text { in the roof. }\end{array}$ & 38. Paste black paper cuts on windows \\
\hline & $\begin{array}{l}\text { 39. Paste black paper cuts } \\
\text { on the bridal chamber. }\end{array}$ & 40. Treat guests with the "ten bowls meal" & \\
\hline
\end{tabular}

Notes: Kang, a traditional heatable brick bed in China;

Tian cave, a small niche on cave wall, it has no specific use but is an important part that makes a sunken courtyard complete; Zhongyi, loyalty.

Table 3

Basic attribute of effective interview samples.

\begin{tabular}{|c|c|c|c|c|c|c|}
\hline $\begin{array}{l}\text { Sample } \\
\text { number }\end{array}$ & Surname/Gender & Village & Age & Education level & Vocation & $\begin{array}{l}\text { The family average } \\
\text { monthly income (RMB) }\end{array}$ \\
\hline ZYC01 & Shang/M & Zhaoyuan & $>75$ & Primary school or less & Farmer & $<500$ \\
\hline ZYC02 & Shang/M & Zhaoyuan & $45-59$ & Junior high school & Farmer & $501-1000$ \\
\hline ZYC03 & Shang/M & Zhaoyuan & $45-59$ & Senior high school/technical secondary school & Farmer & $501-1001$ \\
\hline ZYC04 & Shang/M & Zhaoyuan & $45-59$ & Junior college & $\begin{array}{l}\text { Government } \\
\text { agency/institution } \\
\text { staff }\end{array}$ & $2001-4000$ \\
\hline MSC01 & Yuan/F & Miaoshang & $60-74$ & Primary school or less & Farmer & $501-1000$ \\
\hline MSC02 & $\mathrm{Wu} / \mathrm{M}$ & Miaoshang & $45-59$ & Senior high school/technical secondary school & Farmer & $501-1000$ \\
\hline MSC03 & Zhang/M & Miaoshang & $60-74$ & Junior high school & Farmer & $1001-2000$ \\
\hline MSC04 & Zhang/M & Miaoshang & $60-74$ & Junior high school & Farmer & $501-1000$ \\
\hline QC01 & $\mathrm{Lu} / \mathrm{M}$ & Qucun & $45-59$ & Senior high school/technical secondary school & Farmer & $1001-2000$ \\
\hline QC02 & $\mathrm{Li} / \mathrm{M}$ & Qucun & $45-59$ & Junior high school & Retired & $501-1000$ \\
\hline QC03 & $\mathrm{Li} / \mathrm{M}$ & Qucun & $30-44$ & Junior high school & Farmer & $501-1000$ \\
\hline QC04 & $\mathrm{Li} / \mathrm{M}$ & Qucun & $45-59$ & Junior high school & Farmer & $501-1000$ \\
\hline NGC01 & Ren/M & Nangou & $30-44$ & Senior high school/technical secondary school & Farmer & $2001-4000$ \\
\hline NGCO2 & Ren/M & Nangou & $60-74$ & Junior college & Retired & $2001-4000$ \\
\hline NGC03 & Ren/M & Nangou & $>75$ & Primary school or less & Farmer & $<500$ \\
\hline RMZC01 & Guan/M & Renmazhai & $60-74$ & Senior high school/technical secondary school & Retired & $2001-4000$ \\
\hline RMZC02 & Pan/M & Renmazhai & $45-59$ & Senior high school/technical secondary school & Farmer & $>4000$ \\
\hline RMZC03 & Wang/M & Renmazhai & $45-59$ & Junior high school & Farmer & $501-1000$ \\
\hline RMZC04 & Wang/M & Renmazhai & $>75$ & Primary school or less & Farmer & $<500$ \\
\hline
\end{tabular}

\subsubsection{Changed factors}

The quantity of sunken courtyards is a significant changed factor. Since the 1980s, the number of cave dwellings has shown an overall declining trend; however, the speed of decline varies in different villages. No new sunken courtyard has been built since the 1980s. Among the 19 samples, four still exist; the other five disappeared or were abandoned. For the owners of the 19 sunken courtyards, seven of them continue to live in their courtyards, whereas the other 12 lived there previously. Only in Miaoshang Village are the numbers of sunken courtyards declining at a relatively slow speed. The village and its traditional residences are excellent representatives of cave dwellings in architectural form, quality and local culture. As a site entitled the Provincial Cultural
Relics Protection Unit and the National Key Cultural Relics Protection Unit, any form or construction within this village would be prohibited under the Cultural Relics Protection Law; any new construction should coordinate with existing features and traditional styles. By the end of 2012, Miaoshang Village was listed in the First Batch of Chinese Traditional Villages by the Ministry of Housing and Urban-Rural Development. It can be concluded that administrative means have played an important role in cave dwelling protection.

\subsubsection{Stabilized factors}

Most of the sunken courtyards' areas, residence types, unit numbers, plane layouts and interior arrangements have not 
changed since they were built; these are stable architectural factors. There is a certain exception on ZYCO4 and QC02; they have undergone certain changes in unit number and plane layout for reasons of functionality.

To be specific: (1) This type of cave dwelling has very large areas: the smallest measures $600 \mathrm{~m}^{2}$, and the larger ones can cover an area of more than $1500 \mathrm{~m}^{2}$. (2) The number of units (openings into the cave dwellings) is usually between 8 and 12 openings. The actual number is decided by the area of the site. (3) Among the different possible orientations of the main cave, the residence type can be classified as Dongzhen House ${ }^{1}$, Nanli House ${ }^{2}$, Xidui House ${ }^{3}$ and Beikan House ${ }^{4}$; the largest proportion is Xidui House. The layout and interior arrangement remain stable because the residence type has not changed (Fig. 4).

The stability of the architectural layout of the sunken courtyard is influenced by historical cultural traditions and folk customs governing residential construction. For example, according to one principle, "the temple should be straight in direction; the housing courtyard should not, the houses do not precisely face north or south". The floor plans are decided according to the Eight Diagram Theory ("bagua" in Mandarin). To reflect the hierarchical structure, the main cave is typically larger and is also higher and wider in the upper part. The basic architectural forms of the sunken courtyards are adaptions to the natural environment, chosen by local residents over thousands of years.

\subsection{Architectural decoration}

Excluding ZYC02, all of the architectural decorations in the other 13 existing sunken courtyards have been renewed (see appendix). The traditional materials were replaced by more solid, waterproof materials. Changes in the choice of building decoration materials reflect the historical process of modernization.

\subsubsection{Change process}

The renewal of architectural decoration mainly occurred in the 1970s and 1980s. With the improving economic situation, many measures were undertaken to prevent rain from washing out buildings and causing damage to the sunken courtyards. Reconstruction in the 1970s and 1980s primarily addressed the eaves galleries, cliff surfaces, horse-blocking walls, eaves, cornices, broadsides leading upward to the doors, parts next to the doors, and the lower parts of the caves. Construction peaked in the 1980s, decreasing significantly from the 1990s to 2010. After 2010, an overall renewal of the architectural decoration of sunken courtyards occurred.

\subsubsection{Changed factors}

(1) Factors remaining unchanged after one renewal

The tunnels, archways, eaves galleries, lower parts and interior

\footnotetext{
${ }^{1}$ Dongzhen House, one of the four types of sunken courtyard, is named based on the direction of the main room and is arranged by the bagua. It has a rectangle plan, a main room in the east and a kitchen in the southeast.

2 Nanli House, one of the four types of sunken courtyard, is named based on the direction of the main room and is arranged by the bagua. It has a rectangle plan, a main room in the south and a kitchen in the southeast.

${ }^{3}$ Xidui House, one of the four types of sunken courtyard, is named based on the direction of the main room and is arranged by the bagua. It has a square plan, a main room in the west and a kitchen in the southwest.

4 Beikan House, one of the four types of sunken courtyard, is named based on the direction of the main room and is arranged by the bagua. It has a rectangle plan, a main room in the north and a kitchen in the east.
}

floors did not change because the blue brick masonry was renewed and remained very stable; this is a popular and worthwhile renovation. The cliff surfaces, doors and windows were also very stable; since 2010 , coating paint began to be used on the cliff surfaces, and plastic material began to be used for the windows.

\section{(2) Constantly changing factors}

For the horse-blocking walls and the cornices, the materials used in the 1980s were mainly blue bricks; next, the change to red bricks was made. After 2010, the switch was made back to blue bricks. Eaves were renewed with red tiles in the 1990s; the broadsides leading upward to the doors and parts next to the doors began to change to blue brick in the 1970s. In the 1980s, parts of the windows above furnace surfaces were decorated with white paint; in the 1990s, white paint alone was used without blue brick, to conserve materials. In the mid-1990s, certain porcelain-like coatings were used for beautification reasons. After 2010, with sufficient funds, the broadsides upward to the doors and parts next to the doors were again constructed with blue brick; porcelain-like coatings were no longer used. Since the 1970s, an irreversible change occurred in that coatings and paints applied to interior walls became increasingly complicated. All of these changes improved the safety, durability, practicality and comfort of the architecture.

\subsection{Folk construction customs}

Influenced by a long history, the construction of sunken courtyards is exquisite. This study selected 15 major folk building customs to be discussed in the interviews, as depicted in Table 4 .

According to the results of the investigation and interviews, the disappearance of physical architecture does not have a strong effect on the folklore of construction. "Since there is seldom new construction of sunken courtyards, the folk custom does not change much (ZYC04)." Additionally, the vast majority of people believe that the building folklore cannot change and that it should not (NGC03, ZYC04). "If people would rebuild the sunken courtyard in the future, this construction folklore has the rules that we should follow (NGC01)."

However, because no new sunken courtyard has been built since the 1980s, certain young respondents were not fully knowledgeable of all of the folk customs. For example, "many young people know little about the folklore that is associated with feudalistic superstitions (NGC01)." However, the folklore they know has not changed. For example, young people are knowledgeable about "site investigation," and "orientation," and they know that "the doorway cannot be opposite to the road; " none of these three customs have changed (NGC01).

\subsection{Production and living customs}

The unique building methods used for constructing sunken courtyards led to special production and living customs, this study investigated eight major relevant customs (Table 5).

\subsubsection{Changed factors}

(1) The two customs related to agricultural production, "dry grain on the sunny open ground" and "drip grain through the 'horse-eye hole' in the roof" have gradually disappeared. After 1990, rural house construction peaked, and these two customs no longer exist because people don't live in sunken courtyards any more. Farmers now dry grain on the rooftops of the onestory houses they live in. The process is cleaner and faster 


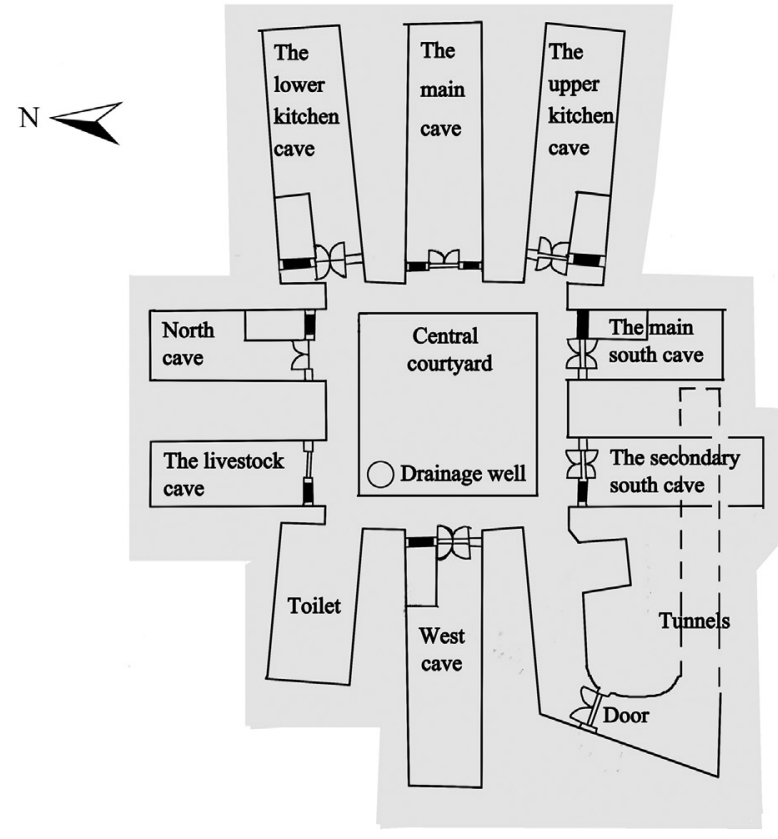

Dongzhen House

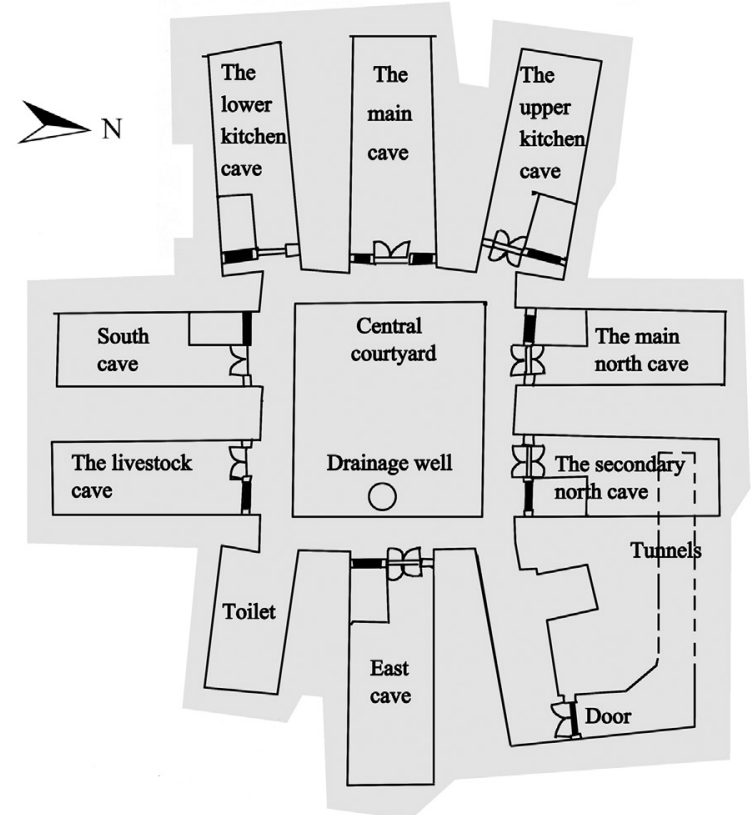

Xidui House

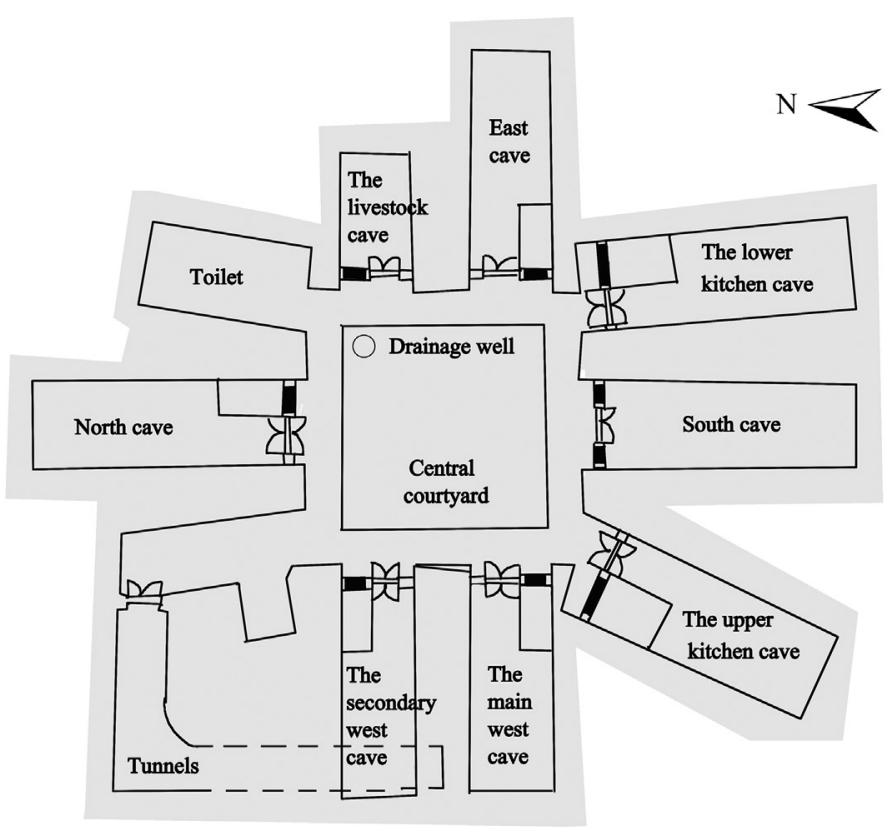

Nanli House

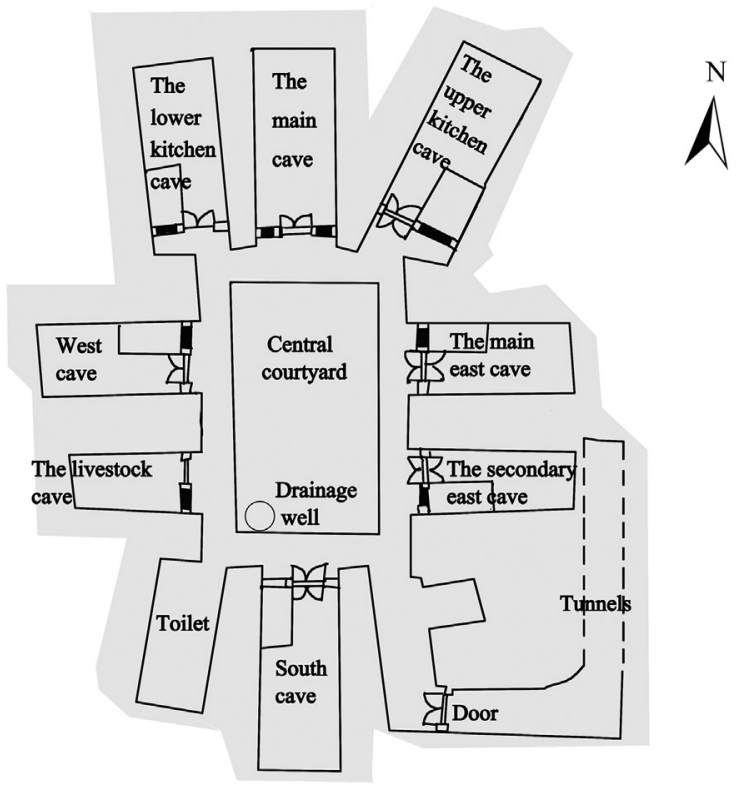

Beikan House

Fig. 4. Schematic plans of Dongzhen House, Nanli House, Xidui House and Beikan House.

(Source: According to Shanxian County in Henan: the main source of China' s sunken courtyard culture, 2009:40-43)

than before, and it takes only two or three days (ZYC02, ZYC03, MSC03). It could be concluded that the change of dwellings resulted in the change of rural production customs. Moreover, changes in agricultural products led to the vanishing of earlier production customs. After the 1990s, many people in this village began to plant apples instead of grain, therefore, they no longer need to dry or drip grain (QC01, MSC02, RMZC01, RMZC02).
Furthermore, although production customs have changed significantly, the people who continue to live in sunken courtyards and plant grain retain the conventions.

(2) The two customs related to daily life, "paste black paper cuts on the window" and "paste black paper cuts in the bridal chamber," have gradually disappeared. Since the 1990s, people seldom pasted black paper cuts on windows because they 
Table 4

Fifteen major building folk customs.

\begin{tabular}{|c|c|c|c|}
\hline Folk customs & Explanation & Folk customs & Explanation \\
\hline 1. Site investigation & The fengshui xian sheng picks a place. & 9. The size of Kang is seven's modules & $\begin{array}{l}\text { In Chinese "seven" and "wife" are homophonic, } \\
\text { implying the wife shall remain in the home. }\end{array}$ \\
\hline 2. Orientation & $\begin{array}{l}\text { Use compass to determine the accurate } \\
\text { orientation of sunken courtyards. }\end{array}$ & 10. The size of cave is five' s module & $\begin{array}{l}\text { Five is the serial number of Earth in the Five } \\
\text { Elements, implying the cave is based on the Earth. }\end{array}$ \\
\hline 3. Create terrain & $\begin{array}{l}\text { Follow the principle of "higher on right side and } \\
\text { lower on left side", the left side of the main cave } \\
\text { is slightly higher than the right side. }\end{array}$ & $\begin{array}{l}\text { 11. The doorway cannot be in } \\
\text { opposition to the road }\end{array}$ & $\begin{array}{l}\text { The entrance of the sunken courtyard shall } \\
\text { not be precisely to the road. }\end{array}$ \\
\hline 4. Direction & $\begin{array}{l}\text { Based on the theory of "The Five Elements", the } \\
\text { property of the house owner should coordinate } \\
\text { with the house itself. }\end{array}$ & $\begin{array}{l}\text { 12. The doorway needs to bend } \\
\text { inward }\end{array}$ & $\begin{array}{l}\text { The gate of the cave shall not be straight, } \\
\text { but it should be built with a certain degree. }\end{array}$ \\
\hline 5. Final closure & $\begin{array}{l}\text { When the construction is completed, the workers } \\
\text { will leave a small niche on top of the main cave, } \\
\text { installing a closure using bricks of red or colored } \\
\text { strings. Then, firecrackers will be lit, and a feast } \\
\text { will be served to wish peace and auspicious to } \\
\text { the master. }\end{array}$ & $\begin{array}{l}\text { 13. The doorway cannot be opposite } \\
\text { the door }\end{array}$ & $\begin{array}{l}\text { The door of the cave shall not be } \\
\text { precisely to the entrance. }\end{array}$ \\
\hline 6. Visit the new yard & $\begin{array}{l}\text { When moved to the new house, friends and } \\
\text { relatives of the owner will visit with gifts. }\end{array}$ & $\begin{array}{l}\text { 14. The door cannot be the } \\
\text { "Door of Exposed Fortune" }\end{array}$ & $\begin{array}{l}\text { Due to the geographic condition, if the doorway } \\
\text { is straight, the stranger will be able to peek at the } \\
\text { main cave; thus this type of door is named } \\
\text { "Door of Exposed Fortune". To avoid the } \\
\text { exposure of family fortune, Zhaobi will be } \\
\text { built at the entrance. }\end{array}$ \\
\hline $\begin{array}{l}\text { 7. Maintain the main } \\
\text { cave as the largest }\end{array}$ & The main cave is the largest by area. & $\begin{array}{l}\text { 15. Civilians' dwelling shall avoid } \\
\text { having a Zhongyi Door }\end{array}$ & $\begin{array}{l}\text { If the doorway is chosen as the location against } \\
\text { the lower side of the main cave, it will be similar } \\
\text { to a royal palace; thus, the doorway is named } \\
\text { the Zhongyi Door. Civilians with houses that have } \\
\text { doors such as this will only bring bad luck to } \\
\text { their family. }\end{array}$ \\
\hline $\begin{array}{l}\text { 8. Build the Tian cave } \\
\text { if no main cave }\end{array}$ & $\begin{array}{l}\text { Tian Cave is the small one on the cliff without } \\
\text { utilitarian role but is the symbol of the } \\
\text { whole courtyard. }\end{array}$ & & \\
\hline
\end{tabular}

Notes: Fengshui xian sheng, the geomancer;

Five Elements, namely, Fire, Earth, Metal, Water and Wood;

Zhaobi, the blocking wall at the entrance;

Table 5

Major production and living customs.

\begin{tabular}{|c|c|c|c|}
\hline Customs & Explanation & Customs & Explanation \\
\hline $\begin{array}{l}\text { 1. Worship gods to } \\
\text { guard against devils }\end{array}$ & $\begin{array}{l}\text { Set niche for the Land God on the wall against } \\
\text { the doorway; set niche for the Heaven God on } \\
\text { the sunny side wall inside the yard; post a } \\
\text { portrait of the Kitchen God on the wall close } \\
\text { to chopping board; post portraits of the Door } \\
\text { God on the cave doors on Spring Festival. }\end{array}$ & $\begin{array}{l}\text { 5. Drip grain through the "horse-eye hole" } \\
\text { in the roof. }\end{array}$ & $\begin{array}{l}\text { "Horse-eye hole" is the ventilation } \\
\text { opening between sunken cave and } \\
\text { ground space. Farmers make grain } \\
\text { drip directly through the hole into } \\
\text { the livestock cave. }\end{array}$ \\
\hline 2. Worship Chinese Toon & $\begin{array}{l}\text { Kids recognize the Chinese Toon in the } \\
\text { courtyard as "Godfather", believing they could } \\
\text { grow taller by shaking the tree while saying } \\
\text { the childish rhyme. }\end{array}$ & 6. Paste black paper cuts on window & $\begin{array}{l}\text { In traditional sunken courtyards, the } \\
\text { window was covered by white paper } \\
\text { rather than glass. Therefore, around } \\
\text { December } 27 \text { th on the Chinese lunar } \\
\text { calendar, people use new white paper } \\
\text { to replace the old one and paste black } \\
\text { paper cuts on it. }\end{array}$ \\
\hline 3. Plant "auspicious" trees & $\begin{array}{l}\text { Pear tree brings fortune, Pomegranate brings } \\
\text { longevity and fertility, whereas Alamo brings } \\
\text { ghosts, Apricot tree means extramarital affairs, } \\
\text { Mulberry means bereavement, etc. }\end{array}$ & 7. Paste black paper cut on bridal chamber. & $\begin{array}{l}\text { Cover the roof with white paper and } \\
\text { then paste black paper cuts on it. }\end{array}$ \\
\hline $\begin{array}{l}\text { 4. Dry grain on the } \\
\text { sunny open ground }\end{array}$ & $\begin{array}{l}\text { In harvest seasons, farmers spread out grain on } \\
\text { the sunny open ground and thresh it after } \\
\text { it has dried. }\end{array}$ & 8. Treat guests with the "ten bowls meal". & $\begin{array}{l}\text { "Ten bowls meal" is the special food } \\
\text { for local residents to hold wedding, } \\
\text { funerals or important celebrations. }\end{array}$ \\
\hline
\end{tabular}

moved into one-story houses with glazed windows, eliminating the need for white paper (ZYC03, MSC01, MSC02, MSC03, QC03, NGC02). Window paper cuts and traditional dwellings declined at the same time (NGC03). Certain residents who continue to live in sunken courtyards with traditional windows covered by paper still paste black paper cuts to them; however, this is an individual preference (NGC03). The custom "paste black paper cuts in the bridal chamber" has also gradually disappeared since the 1990s (NGC02, ZYC02, ZYC04, RMZC03). One reason is that, as living standards improving, people do not need to use black paper cuts for decoration. The rooftops are whitewashed, and landscape paintings and portraits purchased from stores are hung (NGC02). However, the main reason for the disappearance is that brides tend to request to marry in one-story houses 
instead of in sunken courtyards; therefore, they no longer need paper cuts (ZYC02, MSC01, MSC03).

However, with the development of tourism in recent years, the paper cut in sunken courtyards is gaining increasing attention as a decorative art form. Nangou Village, one of the five cases investigated in this study, is particularly famous for its long lasted of paper cutting, which has persisted for more than 300 years. The village has developed a characteristic cultural industry based on these traditional homemade artifacts. With the rise in standard of living, the aesthetic appreciation for paper cutting has changed from a preference for simple black cuts to include more diverse types (Figs. 5 and 6).

(3) The living custom "treat guests with the ten bowls meal" still exists, however, the types of food have improved with the increase in farmers' standard of living resulting from reform and opening-up policies. In the past, food was simple and cheap, such as tofu or fried radish; however, currently, fat meat, lean meat and chicken nuggets are preferred (ZYCO2).

\subsubsection{Stabilized factors}

The living customs related to folk religion, "worship gods to guard against devils," "worship Chinese toon" and "plant auspicious trees" have not changed. Many respondents could speak in detail of the folk rules and taboos of sunken courtyards. Those customs are continued in today's life and have changed little (MSC04).

\section{Discussions}

In light of the change factors analyzed in the previous part, this section summarizes and discusses the phenomena and influences accompanying the disappearance of sunken courtyards. These developments include changes in cultural information and family structure, and they are also closely related to the transformation of rural land policies.

\subsection{Changes in cultural information}

Sunken courtyards are the carriers of local traditional culture. What impact will this have on traditional cultural customs since they are gradually disappearing? Changes in cultural information can be described as follows:

(1) The cultural customs related to construction and folk religion have barely changed, whereas production and living customs have changed greatly. This change has occurred since the 1990s because, increasingly, people have left sunken courtyards and moved into one-story houses.

(2) The cultural customs related to construction and folk religion, as well as living customs such as "treat guests with the ten bowls feast" have not been affected by the departure from sunken courtyards, these customs have remained strong and stable.

(3) The four production and living customs, "dry grain on the sunny open ground", "drip grain through the 'horse-eye hole' in the roof", "paste black paper cuts in the bridal chamber" and "paste black paper cuts on the window" rely on the physical structure of the traditional buildings; therefore, they cease to exist with the disappearance and abandonment of the sunken courtyard. Therefore, it can be concluded that cultural information that is closely related to the physical building is more likely to change or disappear; otherwise, it would have stability.

\subsection{Changes in family structure}

The decay of sunken courtyards has mainly occurred because fewer people want to live in such dwellings. Since the 1980s,
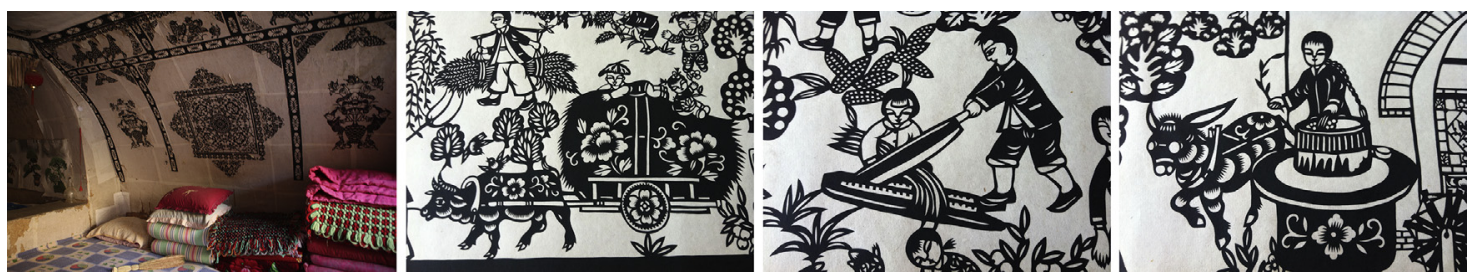

Fig. 5. The black paper cuts in sunken courtyards. (Source: Authors).
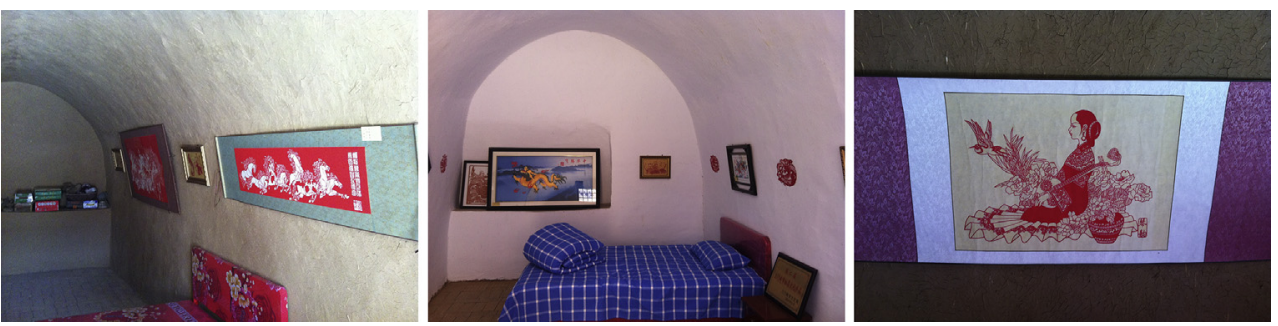

Fig. 6. New colorful paper cuts, machine embroidery and cloth art (Source: Authors). 
F. Wang et al. / Journal of Rural Studies 47 (2016) 630-649

641

increasing numbers of people moved out of their traditional houses, the number of people who continue to live in sunken courtyards shows a declining trend (Figs. 7-11).

This investigation revealed that the residents who still live in sunken courtyards are mainly elderly people. Members of the young generation spend most of their time working outside of the village and return only occasionally. Rural family structure is transforming from a multi-generation model to a nuclear family type. Drawing on interviews with 19 respondents regarding their family members' moving-out processes after 1980, focusing pimarly on function, the reasons why residents moved out of their sunken courtyards can be summarized as follows:
(1) Children transferred to other schools outside the county. (2) Adult family members obtained jobs outside the county. (3) Brides requested that male youths provide one-story houses in order to marry. (4) Female youths moved into one-story houses after marrying. (5) As the young generation grew up, got married and produced offspring, the space was insufficient for the increase in number of family members.

5.3. Influence of rural policy

This investigation into the five case areas demonstrates that the gradual changes in sunken courtyards are closely related to the

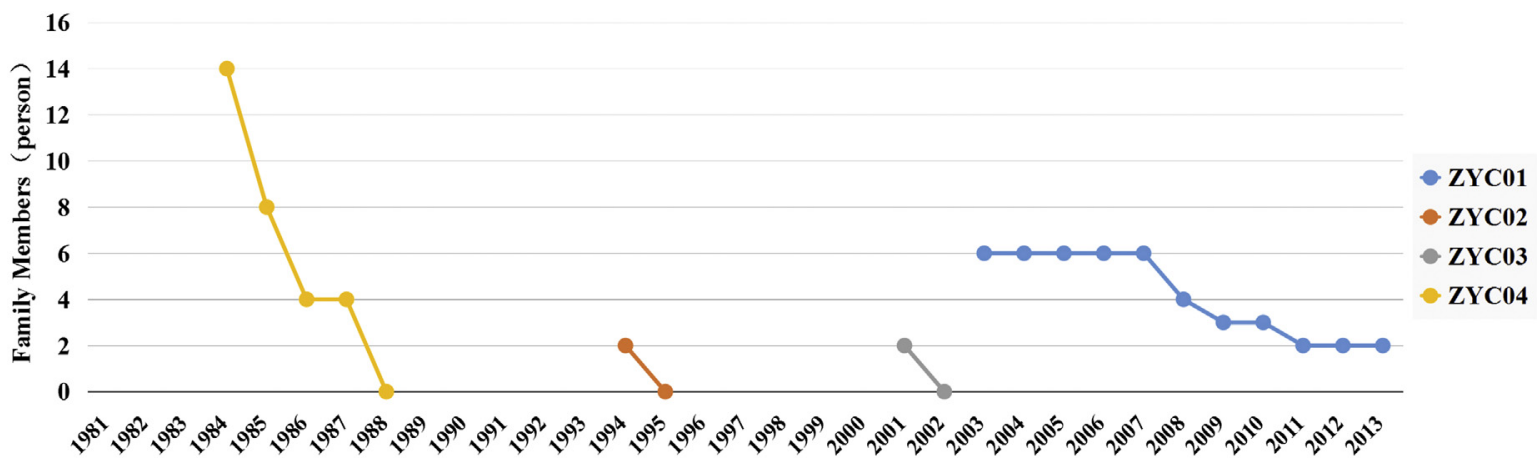

Fig. 7. The declining tendency of family members in Zhaoyuan Village. (Source: Authors)

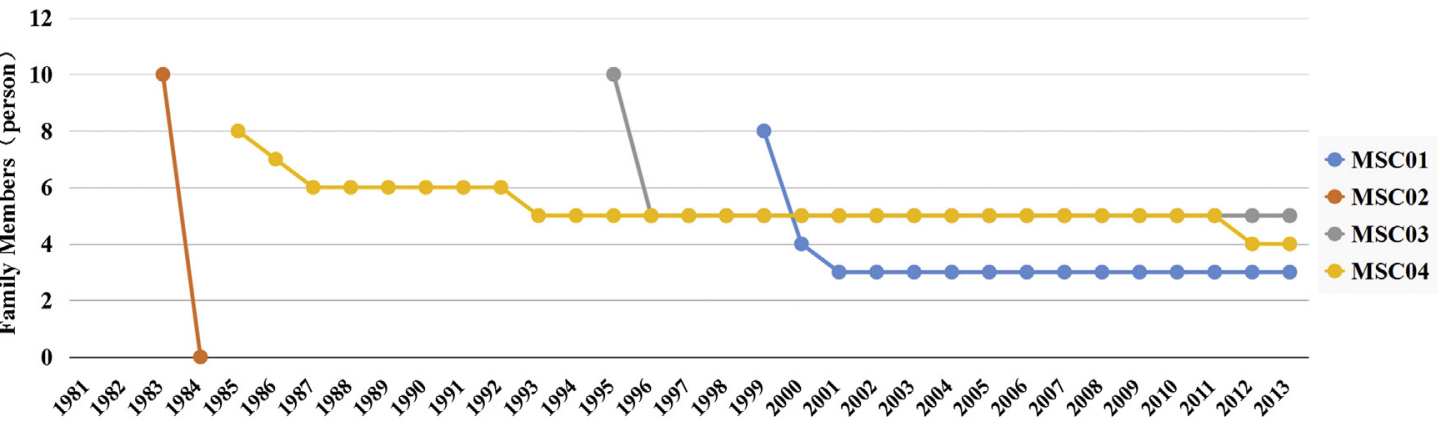

Fig. 8. The declining tendency of family members in Miaoshang Village. (Source: Authors).

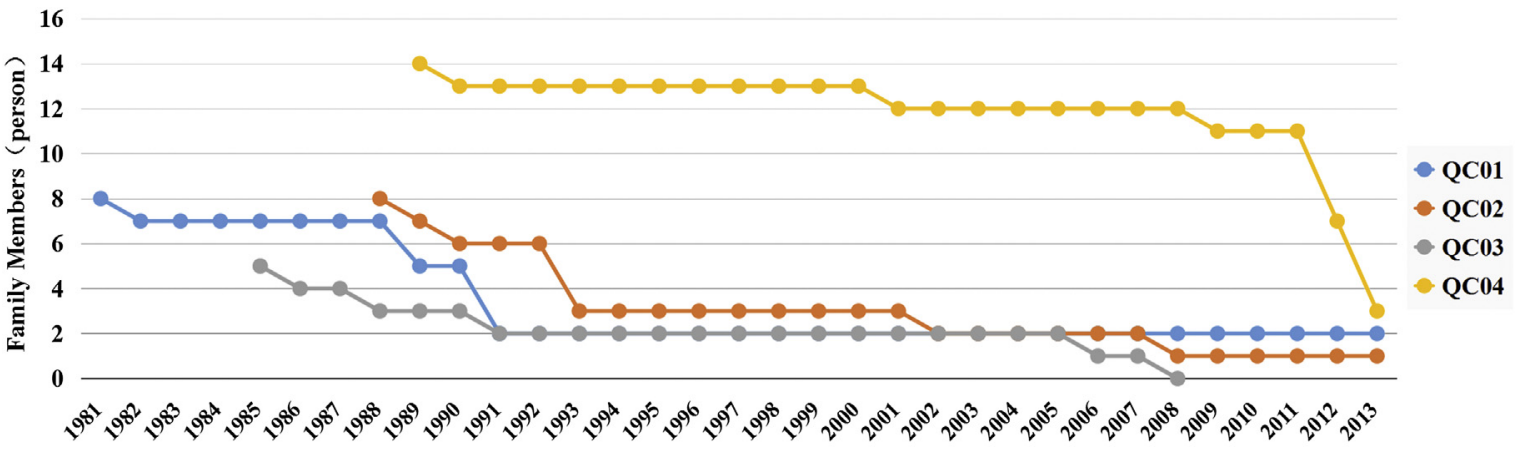

Fig. 9. The declining tendency of family members in Qucun Village. (Source: Authors). 


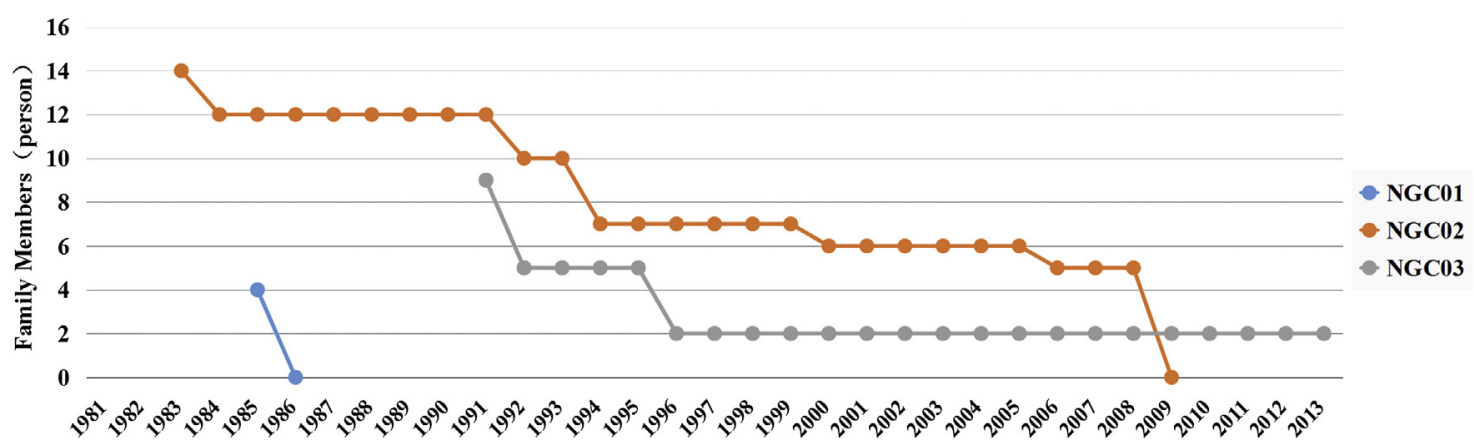

Fig. 10. The declining tendency of family members in Nangou Village. (Source: Authors).

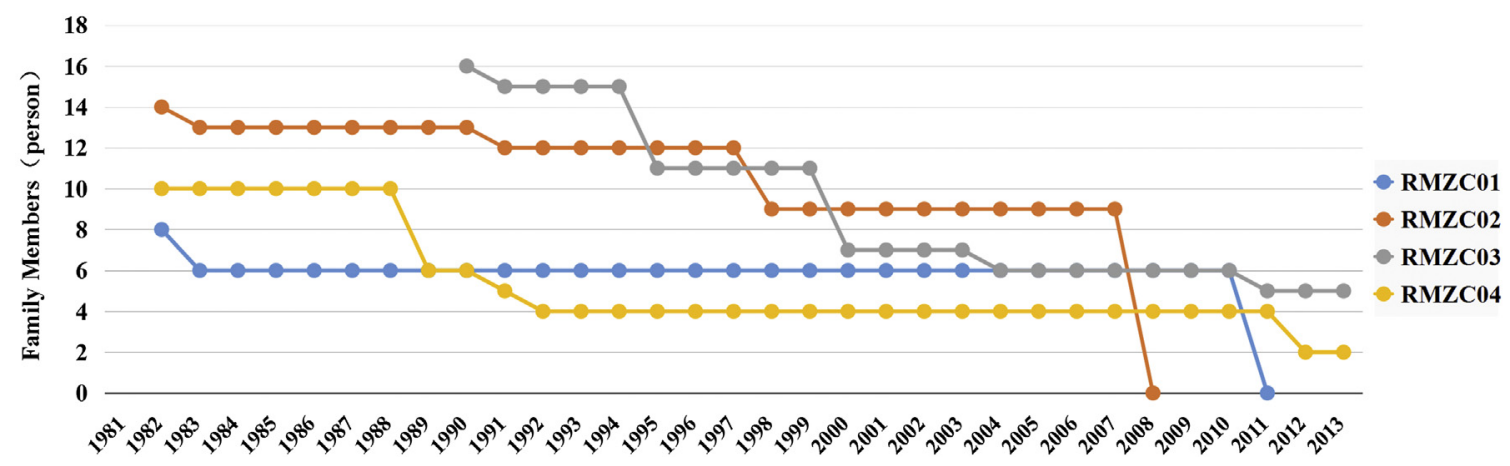

Fig. 11. The declining tendency of family members in Renmazhai Village. (Source: Authors).

transformation of rural land policies.

(1) After the $1980 \mathrm{~s}$, stricter policies regarding homestead applications were enacted; villagers no longer had sufficient space to build new sunken courtyards. On December 29th, 1982, the Shanxian local government announced the Measures for Implementing Rural Land House Construction in Shanxian County, which regulated the acreage of homesteads, limiting each family to approximately $0.3 \mathrm{mu}\left(200 \mathrm{~m}^{2}\right)$. In 1987, the Measures for the Implementation of the Land Administration Law in Henan Province stipulated that, for a family with two boys, if they already had a homestead area of more than $0.3 \mathrm{mu}$, their application for a new homestead would not be approved. Due to the limitations imposed by land policies, farmers could not dig new sunken courtyards, but had to build smaller one-story houses. Once the family moved into a new house, people thought the old dwellings were useless and abandoned them; the grass began to grow lush, and after two or more years of neglect, the caves could collapse (QC02).

(2) The policy "Conversion of Residential Land into Farmland in Shanxian County" had the objective of saving and protecting arable farmland; however, it also accelerated the disappearance of sunken courtyards. After the 1980s, farmers were eager to improve their living conditions and built modern one-story houses one after another. Consequently, the number of abandoned sunken courtyards increased, which was a great waste of land resources. To change this situation and redevelop land resources, the policy was implemented in Shanxian County in 1992. From 2002 to 2004, the county invested 6.3 million RMB to deal with the "hollow village" phenomenon; and an additional $3400 \mathrm{mu}$ (2.26 million $\mathrm{m}^{2}$ ) of farm land became available while more sunken courtyards disappeared (data from Bureau of Land Resources, Shanxian County). The demolition of one sunken courtyard allowed the acquisition of another $0.3 \mathrm{mu}\left(200 \mathrm{~m}^{2}\right)$ homestead area for a one-story house (RMZC04). Both the public authorities and individual owners demolished the old sunken courtyards. These courtyards were destroyed, thus, the cave culture in China may soon perish (NGC01). The people who continue to live in sunken courtyards are primarily lonely elderly people in disadvantaged economic conditions (NGCO2).

\section{Conclusions}

This study set out to provide an analysis of factors causing the gradual disappearance of sunken courtyards in Shanxian County, revealing the driving forces behind the decline. The reasons involve the limitations of heritage, ideas, management and policy:

(1) The defects and limitations of the sunken courtyard. The transformation of household production, practices and livelihoods has brought inevitable changes in communities' vernacular dwellings. Houses are required to accommodate new activities. The sunken courtyard is very inconvenient to enter and exit, and residents have to go up and down to obtain water, dispose of garbage, or carry apples. Addition- 
ally, sunken courtyards are usually damp and dark and are insecure after heavy rains, which makes them prone to collapse. With their living standards improving, farmers began to demand better housing conditions more forcefully. Compared with traditional dwellings, above-ground houses are more suitable for modern lifestyles. All of these features hindered the development of traditional cave dwellings.

(2) Changes in ideas of lifestyle and the loss of local attachments. Influenced by urbanization, people embraced flats and apartments, regarding them as symbols of a modern lifestyle. In contrast, sunken courtyard became a symbol of poverty and shabbiness, thus causing the feeling of frustration. Vernacular architecture is more than a heritage from the past, it forms a local identity and represents a town's special and unique characteristics, distinguishing it from other places. When these identity characteristics are no longer recognized by local residents, corresponding changes in vernacular architecture happen.

(3) The lack of proper management and maintenance. An increasing number of people have moved away from sunken courtyards since the 1980s, and the population living in them has decreased. In the villages of the 19 sunken courtyards studied here, the highest population was once 174 people, whereas there are currently 29 people. The destruction of the traditional family structure also accelerated the disappearance of sunken courtyards. Maintenance seldom occurs after people move out. Affected by weeds and soaked by rainfall, many sunken courtyards collapsed or were damaged so badly that they could no longer be used, they were then buried and converted into farmland or flats. This process is how sunken courtyards disappeared.

(4) Policy changes, including the limitation of homestead approvals and land use consolidation policy based on the replacement of housing areas with farmland. As previously noted, since 1982, homestead limitations have been set to approximately $0.3 \mathrm{mu}$ per home, which restricts new sunken courtyard construction. Furthermore, as the main policy for land development and consolidation, the policy of replacing housing with farmland accelerated the disappearance of the sunken courtyard. Additionally, from 2002 to 2008, more cave dwellings disappeared in the movement to regulate "hollow villages".

This study suggests that the gradual disappearance of sunken courtyards in Shanxian County was an inevitable historical process. With the rapid development of urbanization, popular ideology has changed greatly. History rolls forward with an irresistible force, the physical forms of buildings change to adapt to new styles of production and living. It is obvious that the traditional sunken courtyards could no longer satisfy the demands of local residents' modern lifestyles. However, as an important rural heritage that could strengthen the sense of locality, the sunken courtyard's cultural value should not be ignored. The protection of sunken courtyards should be based on a comprehensive understanding of residents' functional, spiritual and social needs and should focus on the combination of economic benefits and humanistic qualities.

Future protection and development programs should pay attention to the authenticity and integrality of dwellings following a dynamic, staged, hierarchical and multipath renewal principle. To achieve preservation, sunken courtyards will require material protection and maintenance, as well as the promotion of practical, functionality for living. From the maintenance of heritage exterior repair techniques to renewing the spiritual culture surrounding the sunken courtyard, preservation will require not only the continuation of traditions but also innovation and creation.

The following objectives are clear: (1) For material maintenance, the goals should be keeping traditional ecological building materials; preserving the architectural forms and decorative features of sunken courtyards; repairing existing damage by following traditional folk construction customs, as well as by responding to changed situational factors; growing plants to preserve soil and water; and preventing irreparable damage. (2) For maintenance through use, on the one hand, the goal should be strengthening the construction of infrastructure to maintain the structures' functionality for living. On the other hand, preservation demands developing new functions that respond to specific characteristics of each different village (such as developing a traditional art museum in Nangou Village for its famous paper cutting art). (3) To maintain folklore customs, the key points are to maintain rural vitality and to enable the original residents to stay. Furthermore, developing experience-based tourism projects could also contribute to the continuation of customs.

In addition, the government could introduce appropriate policy measures to facilitate the protection and renewal process. For instance, on the land-use management level, heritage protection hierarchical plans could be tailored to each current preservation situation. On the tourism development level, programs can invest in traditional cultural industries, such as creating historical and cultural museums, traditional art studios or heritage research centers with sunken courtyards. On the education and cultural communication level, plans can aim to enhance policy support for cultural propaganda and rural heritage research and to collaborate with schools to make the young generation more aware of the value of these cave dwellings. In brief, the planning goal is to form a dynamic dwelling protection model following the path of authenticity protection, reasonable renewal, appropriate development and rural revitalization.

Further studies could focus on three aspects. First, the quantity of cave dwellings to be preserved: How many should be fully preserved, and how many could see rebirth? Second, the boundaries of heritage protection areas: How should the scope of protection be delimited to maintain a balance between conservation and development? Third, the properties of existing sunken courtyards: Should their protection aim to keep them in a static state of preservation or should they be used for tourism development? How can their roles as heritage carriers be made to correspond to their importance for conveying cultural information? Deeper studies exploring flexible and pragmatic approaches to finding multiple uses for traditional heritage sites will help improve the maintenance and management of sunken courtyards.

\section{Acknowledgement}

This study was supported by the National Natural Science Foundation of China (Grant No. 51078003).

\section{Appendix. The architectural decoration's change of sunken courtyards in Shanxian County}


Samples The changes to architectural decorations of sunken courtyards over time

ZYC01
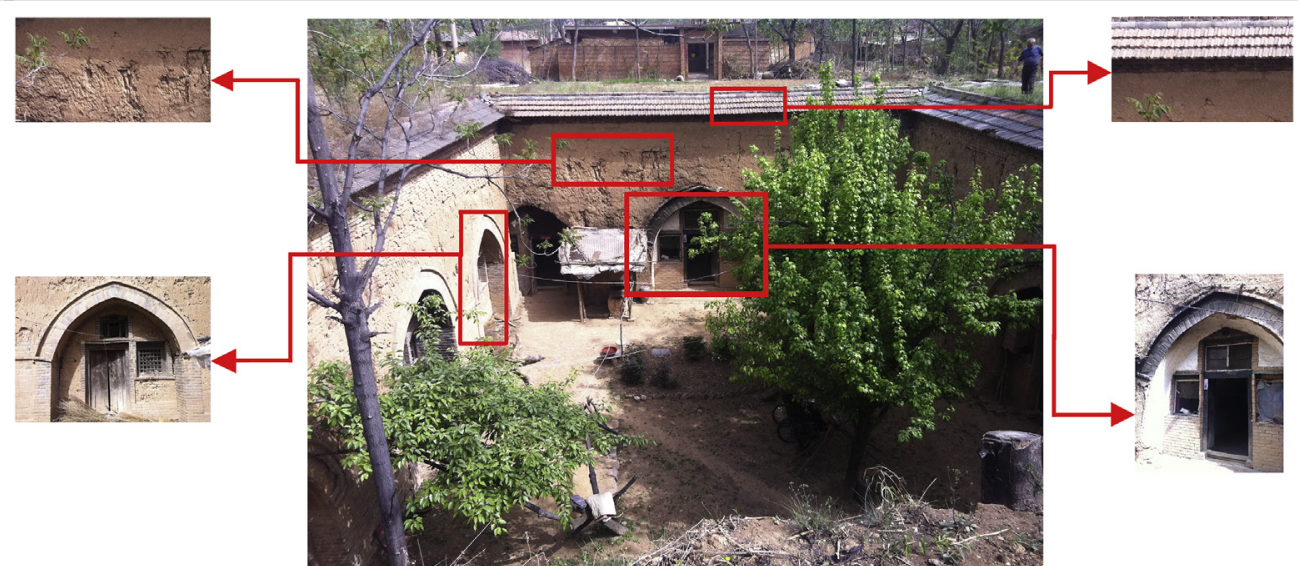

Use the cob to re-plaster the cliff face; construct new gray-green roof tiles on the eaves; put red bricks on the cornice; make the broadside brickworks upward to the door; use black bricks for parts next to the door and the nether parts; use the lime to brush parts next to the door and the internal wall (1982).

ZYC04
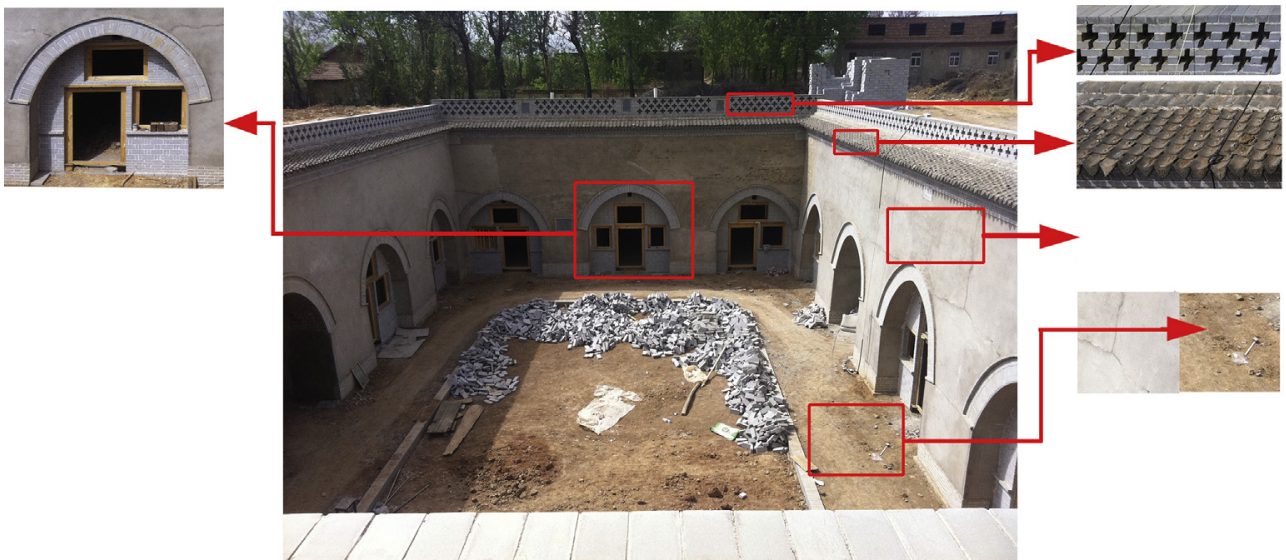

Pave the tunnel and archway with brickworks; use the cob to re-plaster the cliff face; above the cement, brush the face with the earth yellow coating; make brickworks of the eaves gallery and interior wall; construct new gray-green roof tiles on the eaves; use PVC as the materials for the window bar, and install vitreous windows; use interior wall paint with a white tile-like coating (2012).

MSC01
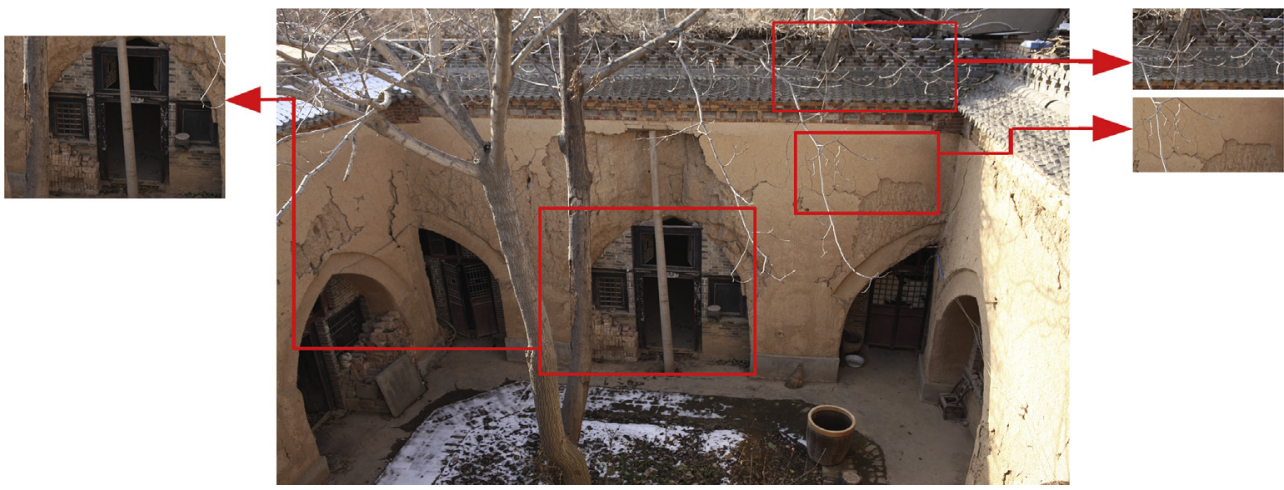

Use the cob to re-plaster the cliff face; use adobe for the masonry horse-blocking wall; make broadside brickworks of upward to the door of the secondary north cave (1980). 
(continued)

Samples The changes to architectural decorations of sunken courtyards over time

$\mathrm{MSC03}$
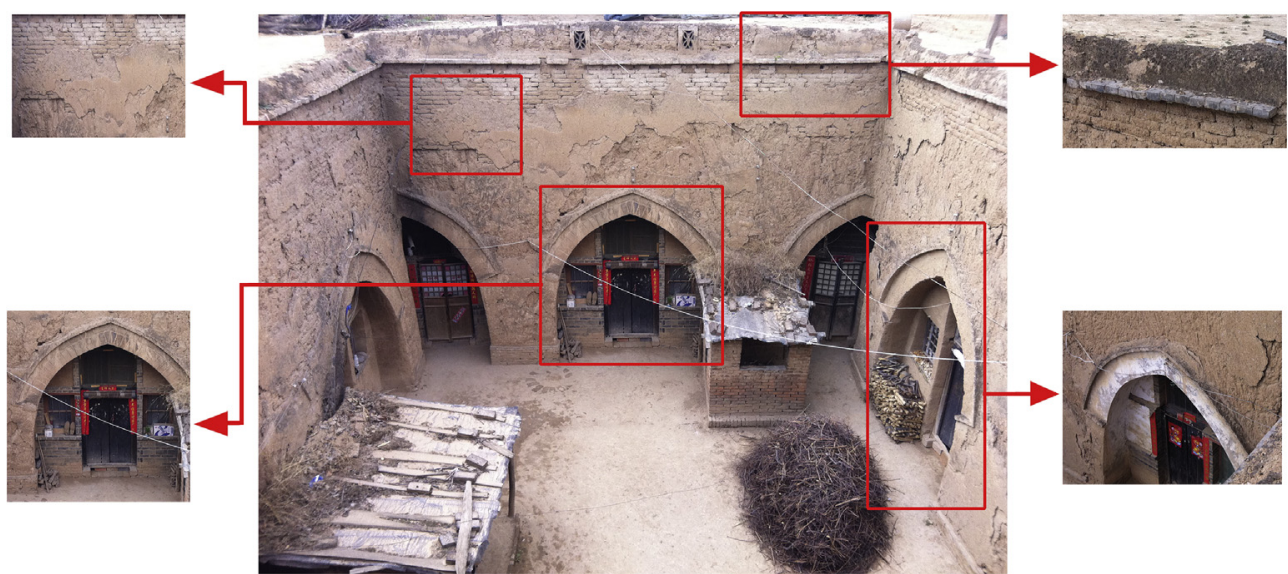

Use the cob to re-plaster the cliff face; use adobe for the masonry horse-blocking and cornice wall; the main cave's broadside upward to the door and parts next to the door; make brickworks of the lower parts; install glass windows (1975); make the parts next to the door of the main cave using blue brick; pave the indoor ground with blue bricks (1996).

MSC04
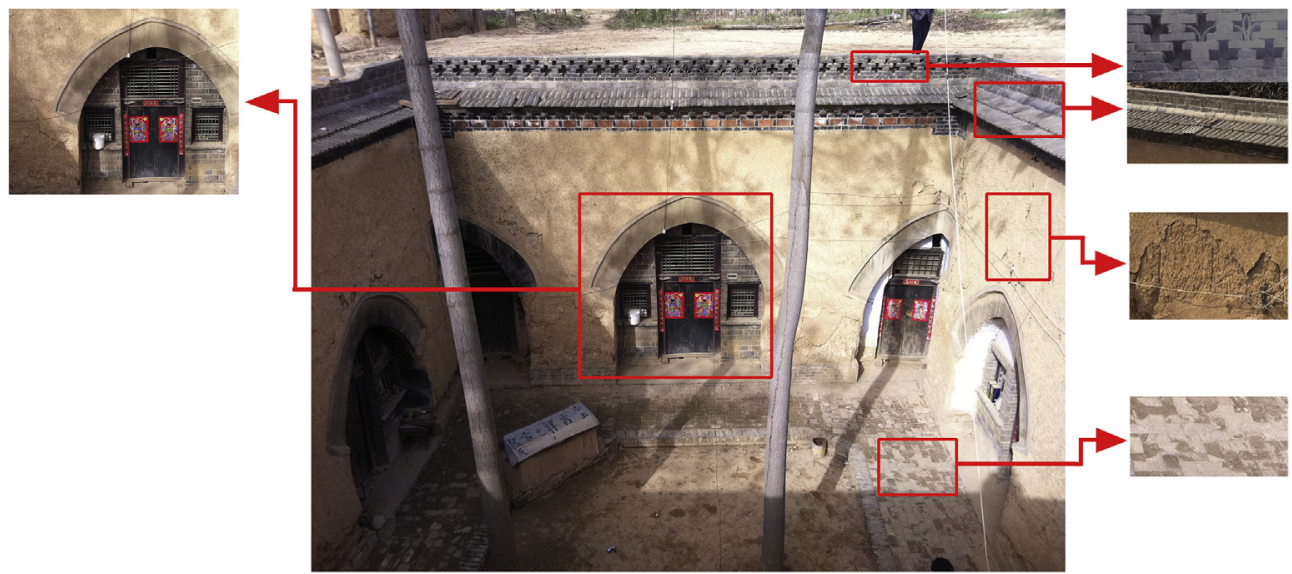

Use the cob to re-plaster the cliff face (1964); make brickworks of the tunnel and archway; Use the cob to re-plaster the cliff face and interior wall; pave the eaves gallery and indoor ground with blue bricks; construct new gray-green roof tiles on the eaves; use the cob to re-plaster the cliff face again; plaster broadside upward to the door with cement; use black bricks to make brickworks of the parts next to the door and of the lower parts (1978).

QC01
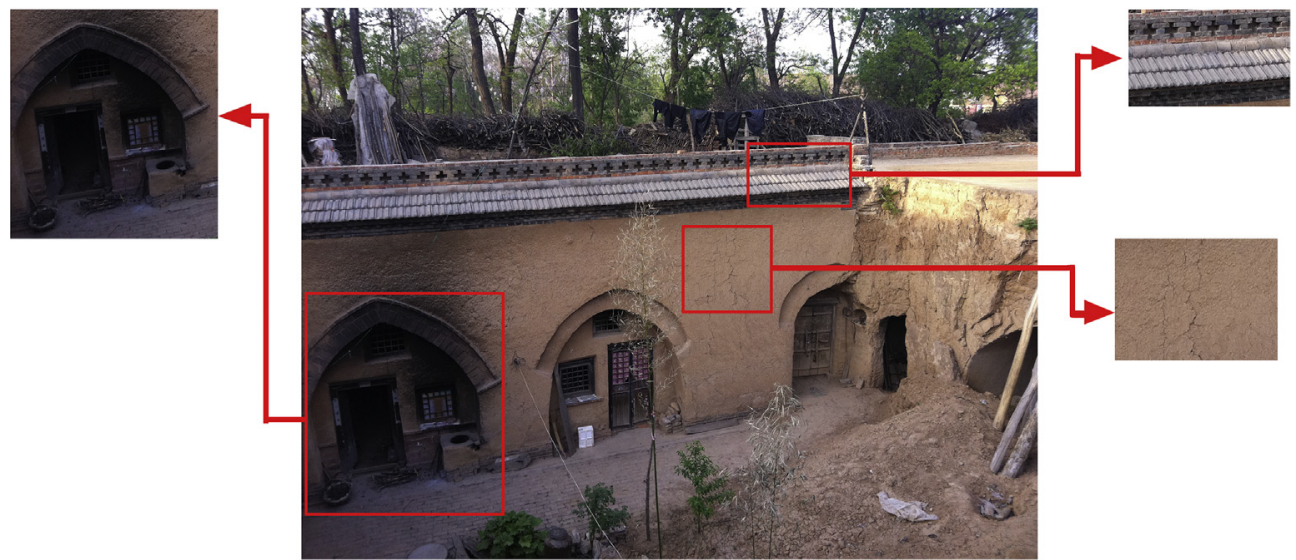

Use the cob to re-plaster the cliff face; construct new red roof tiles on the eaves; masonry horse-blocking and cornice wall use red brick; use red brick to make the parts next to the door and lower parts; use the lime to brush the internal wall (1975). 
(continued)

Samples The changes to architectural decorations of sunken courtyards over time

QC02
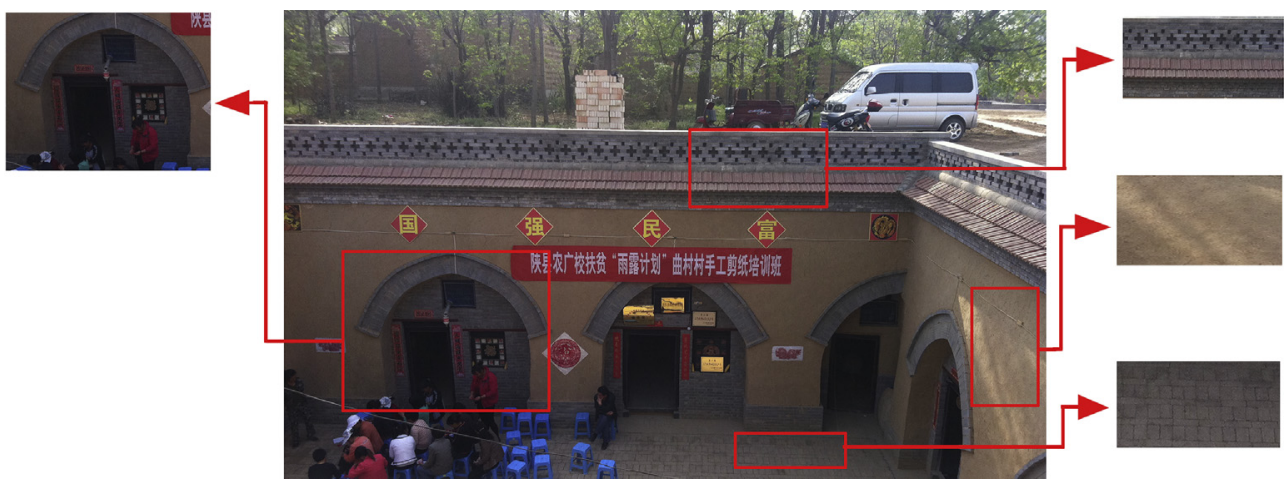

Pave the tunnel and archway with brickworks; use the cob to re-plaster the cliff face; make eaves gallery of blue brick; construct new red roof tiles on the eaves; make horse-blocking wall and cornice of blue brick; make brickworks of broadside upward to the door and parts next to the door and lower parts with black bricks; install the glass window; paint interior wall with white tile-like coating (2012).

QC04

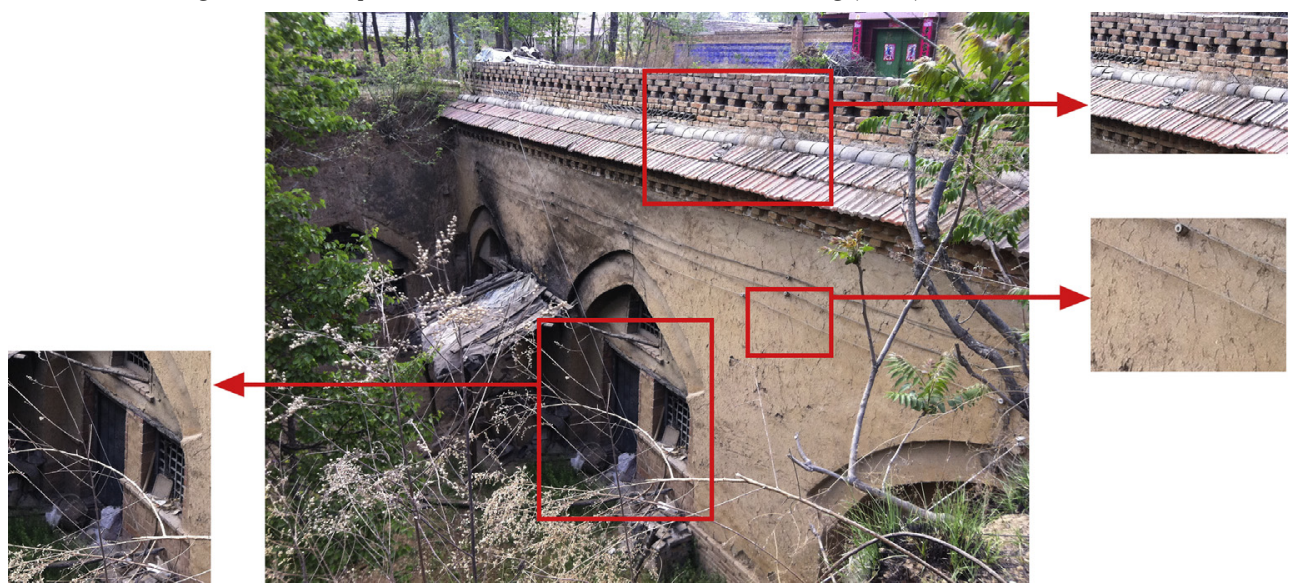

Use the cob to re-plaster the cliff face; make eaves gallery of blue brick; construct new red roof tiles on the eaves; make horse-blocking wall and cornice of blue brick; use black bricks to make brickworks of broadside upward to the door and parts next the door and lower parts (1995).

NGC02

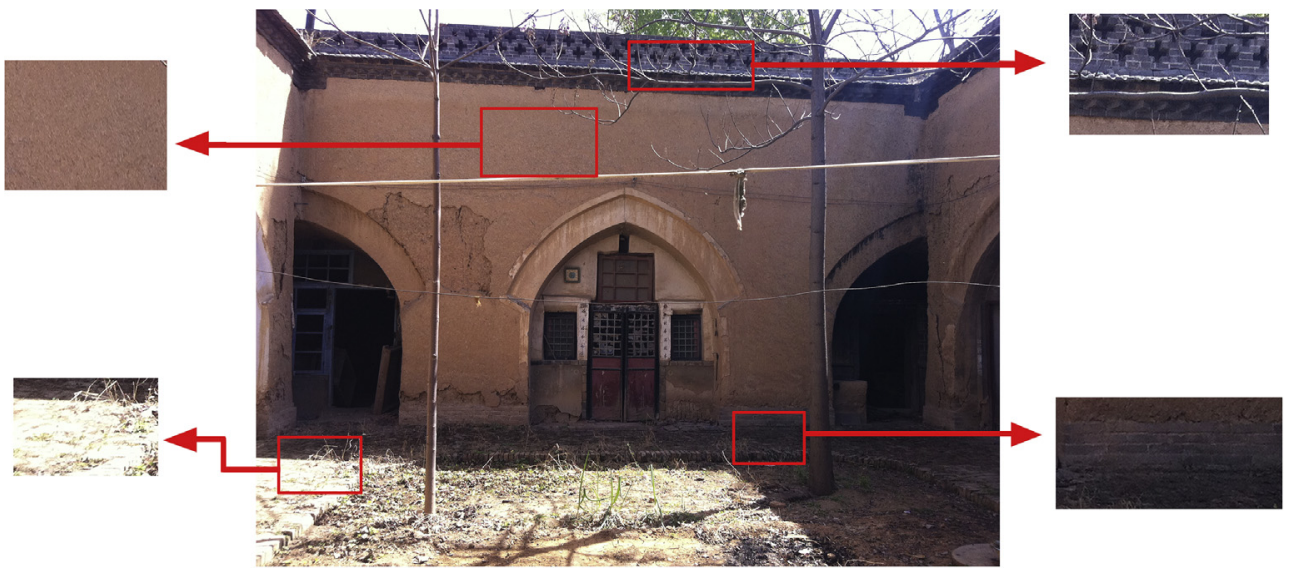

Pave the tunnel and archway with brickworks; use the cob to plaster the cliff face again; make eaves gallery of blue brick; construct new gray-green roof tiles on the eaves; make horse-blocking wall and cornice of blue brick; paint the second main cave's doors and windows in blue paint (1975); paint the main east cave's interior wall with white paint; install glass windows in the main west cave and the secondary west cave (1990); use the white tile-like coating and blue paint to brush parts next to the door and the internal wall; use the lime to brush broadside upward to the door; install the glass windows and wooden door; pave the indoor ground with blue bricks (1995); the main east cave interior wall and broadside upward to the door paint with white tile-like coating (2000). 
(continued)

Samples The changes to architectural decorations of sunken courtyards over time

NGCO3
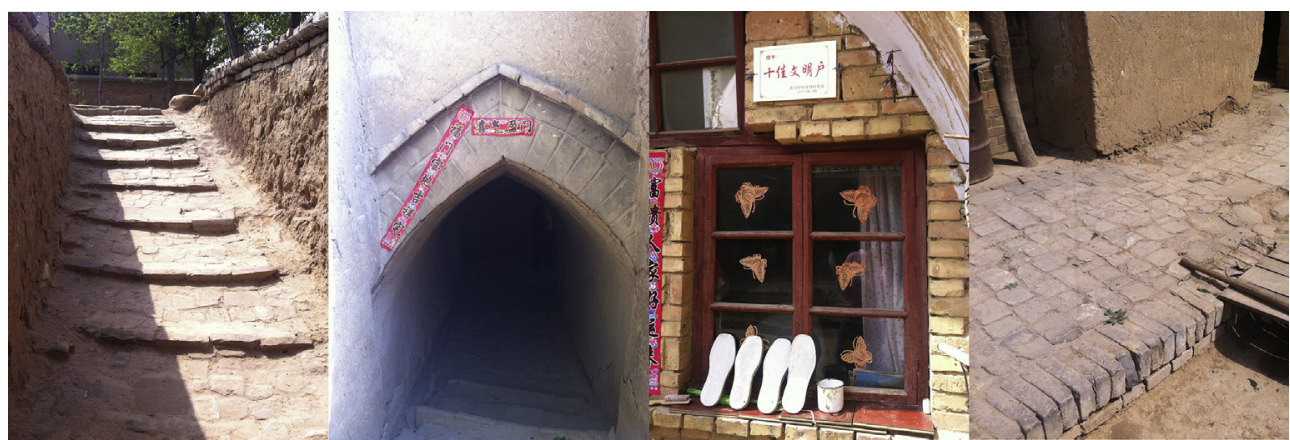

Pave the tunnel and archway with brickworks; paint the interior wall with white paint; install the glass window (1988); construct new gray-green roof tiles on the eaves; make horse-blocking wall with red brick (2000).

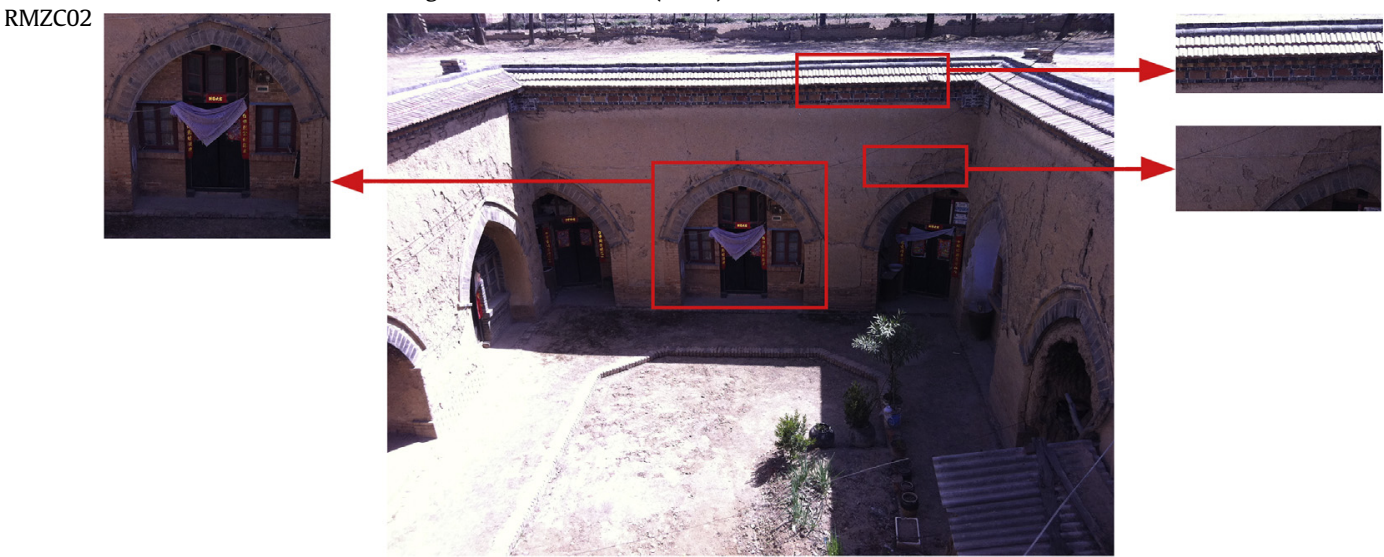

Pave the tunnel and archway with brickworks; use the cob to re-plaster the cliff face; construct new gray-green roof tiles on the eaves; make horse-blocking wall and cornice of blue brick; make brickworks of broadside upward to the door and parts next to the door and lower parts with black bricks (1985); install the screen window (1999).

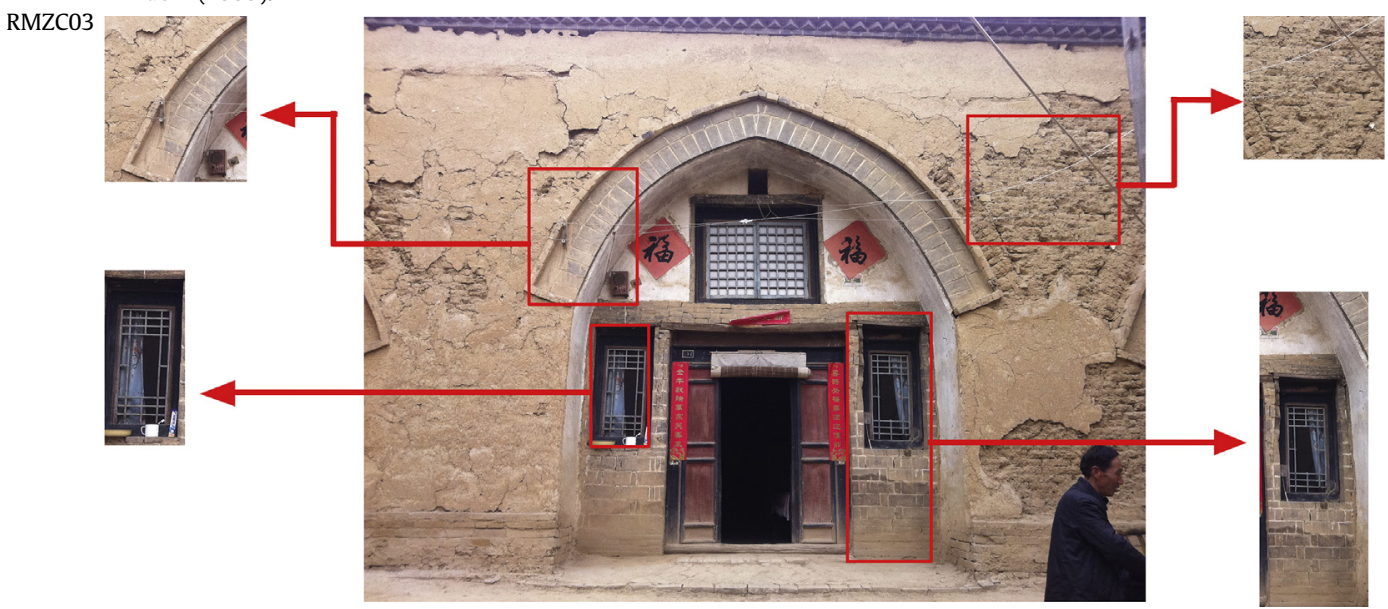

Use the cob to re-plaster the cliff face; construct new gray-green roof tiles on the eaves; make horse-blocking wall and cornice of blue brick; install the glass window; use black bricks to make brickworks of broadside upward to the door and parts next the door and lower parts; install the glass window (1982). 
(continued)

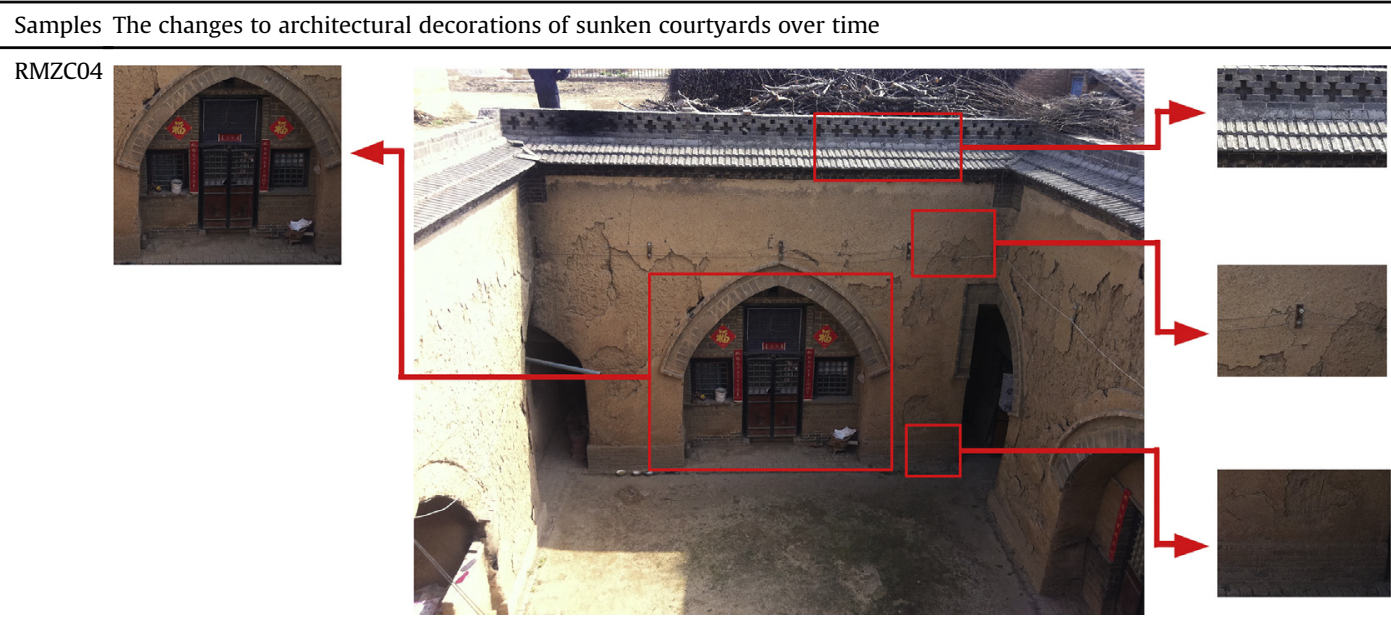

Use the cob to re-plaster the cliff face; construct new gray-green roof tiles on the eaves; use black bricks to make brickworks of broadside upward to the door and parts next to the door and lower parts (1983); install the glass window; sand interior wall with gray paint; pave indoor ground with blue bricks (1988).

\section{References}

Al-Naim, M., Mahmud, S., 2007. Transformation of traditional dwellings and income generation by low-income expatriates: the case of Hofuf, Saudi Arabia. Cities 24 (6), 422-433.

Al-Naim, M.A., 1998. Potentiality of the Traditional House: a Case of Hofuf GCC Folklore Center. Al-hasa, Doha.

Al-Temeemi, A.A., Harris, D.J., 2004. A guideline for assessing the suitability of earth-sheltered mass-housing in hot-arid climates. Energy Build. 36, 251-260.

Barbero-Barrera, M.M., Gil-Crespo, I.J., Maldonado-Ramos, L., 2014. Historical development and environment adaptation of the traditional cave-dwellings in Tajuña's valley, Madrid, Spain. Build. Environ. 82, 536-545.

Benardos, A., Athanasiadis, I., Katsoulakos, N., 2014. Modern earth sheltered constructions: a paradigm of green engineering. Tunn. Undergr. Space Technol. 41, 46-52.

Bodach, S., Lang, W., Hamhaber, J., 2014. Climate responsive building design strategies of vernacular architecture in Nepal. Energy Build. 81, 227-242.

Chen, C., Liu, Y.S., 2014. The spatio-temporal patterns of urbanization of China's agricultural area and its influential factors: the case of Henan Province. Econ. Geogr. 34 (12), 48-54 (in Chinese).

Chen, Z.H., He, Y.N., 2010. Modern western building and social change of overseas Chinese hometown in south of Fujian. Huazhong Archit. 32 (6), 122-125 (in Chinese).

Chuapram, S., King, R., Panin, O., 2012. Transformation of local living: Buddhist Thai communities and vernacular houses around Songkhla Lake basin. Soc. Behav. Sci. 50, 42-54.

Dong, J.Y., Jin, 2013. The design strategy of green rural housing of Tibetan areas in Yunnan, China. Renew. Energy 49, 63-67.

Erdem, A., 2008. Subterranean space use in Cappadocia: the Uchisar example. Tunn. Undergr. Space Technol. 23, 492-499.

Fang, Y.G., Liu, J.S., 2009. Cultural landscape evolution of cluster agricultural village: the case of Yukou village in Shandong Province. Geogr. Res. 28 (4), 968-978 (in Chinese).

Fatimah, T., 2015. The impacts of rural tourism initiatives on cultural landscape sustainability in Borobudur area. Procedia Environ. Sci. 28, 567-577.

Foruzanmehr, A., 2015. People' s perception of the loggia: a vernacular passive cooling system in Iranian architecture. Sustain. Cities Soc. 19, 61-67.

Gao, C.Z., Tian, W.L., 2013. The ecological strategy of the pit house in western Henan. Adv. Mater. Res. 671, 2264-2267.

GhaffarianHoseini, A., Berardi, U., Dahlan, N.D., GhaffarianHoseini, A., 2014. What can we learn from Malay vernacular houses? Sustain. Cities Soc. 13, 157-170.

Gou, S.Q., Li, Z.R., Zhao, Q., Nik, V.M., Scartezzini, J.L., 2015. Climate responsive strategies of traditional dwellings located in an ancient village in hot summer and cold winter region of China. Build. Environ. 86, 151-165.

Günçe, K., Ertürk, Z., Ertürk, S., 2008. Questioning the "prototype dwellings" in the framework of Cyprus traditional architecture. Build. Environ. 43, 823-833.

Guo, F., Wu, J.F., Wang, X., Li, L., 2011. Analysis on the world nature heritage value of the Loess Plateau. J. Arid Land Resour. Environ. 25 (8), 24-28 (in Chinese).

Hanan, H., 2012. Modernization and cultural transformation: the expansion of traditional Batak Toba house in Huta Siallagan. Procedia - Soc. Behav. Sci. 50, $800-811$.

Hassan, A.M., Lee, H., 2014. A theoretical approach to the design of sustainable dwellings in hot dry zones: a Toshka case study. Tunn. Undergr. Space Technol. 40, 251-262.

Hou, J.Y., Wang, J., 1999. Yao-dong in China. Hennan Science and Technology Press,
Zhengzhou (in Chinese).

Kuang, J., Zeng, X., 2007. Changes of Dai people's traditional architecture culture and the countermeasures, take the Tuzhangfang of Xinping County in Yunnan as an example. J. Chuxiong Normal Univ. 22 (5), 58-61, 72. (in Chinese).

Li, T.Y., 2012. Research on Modern Changes of Bai Ethnic's Dwellings in Dali Prefecture. Master Dissertation. Shanxi Normal University, Xi'an (in Chinese).

Liu, Y.S., Zhou, Y., 2015. Challenges and countermeasures for beautiful countryside construction in China. J. Agric. Resour. Environ. 32 (2), 97-105 (in Chinese).

Long, H.L., 2014. Land consolidation: an indispensable way of spatial restructuring in rural China. J. Geogr. Sci. 24 (2), 211-225.

Long, H.L., Li, Y.R., Liu, Y.S., Woods, M., Zou, J., 2012. Accelerated restructuring in rural China fueled by 'increasing vs. Decreasing balance' land-use policy for dealing with hollowed villages. Land Use Policy 29, 11-22.

Long, H.L., Woods, M., 2011. Rural Restructuring under Globalization in Eastern Coastal China : What can we learn from Wales? J. Rural Community Dev. 6 (1) 70-94.

Lu, Y.D., 2007. Researches on Chinese folk house in the recent fifty years. Archit. J. 11, 66-69 (in Chinese).

Ma, Z.L., 2010. The Villages Underground in Western Henan Province are Disappearing. China Cult. Dly. Dec 13th, p. 004 (in Chinese).

Moldovan, I.M. Ilies, N.M., Moldovan, S.V., 2015. The reinvention of the traditiona home 'bordei' and its impact on the rural landscape and environment. Agric Agric. Sci. Procedia 6, 479-485.

Osasona, C.O., Ewemade, F.O., Brebbia, C.A., 2010. The Changing Faces of the Concrete Balustrade in Nigerian Vernacular Architecture: International Conference on Sustainable Tourism. Ashurst, New Forest, England, pp. 395-409.

Piedecausa, B., Chinchón, S., 2015. Radon measurements in the cave houses of Crevillente (Spain). Indoor Built Environ. 24 (2), 201-213.

Pi, X.R., 2008. Research for evolution and social factors of the traditional vernacular housings of Nanzhang. Dissertation. In: Xiangfan: Taking the Civil Building Groups of Feng as an Example. Huazhong University of Science and Technology, Wuhan (in Chinese).

Qin, J.Q., 2010. The Research of Yao Dong Architecture Protection and Development in Shanxian County in Sanmenxia. Master Dissertation. Chang'an University, Xi'an (in Chinese).

Rakowski, C.A., 1995. The struggle for housing in rural Venezuela: ideology, practice and power. Rural. Sociol. 60 (1), 129-148.

Saljoughinejad, S., Sharifabad, S. Rashidi, 2015. Classification of climatic strategies, used in Iranian vernacular residences based on spatial constituent elements. Build. Environ. 92, 475-493.

Shan, D.Q., 2004. From Traditional Dwelling to Regional Architecture. China Architecture and Building Press, Beijing (in Chinese).

Shang, G.R., 2011. Reflections on the Group Article. China Books Publishing House, Shenzhen (in Chinese).

She, Z.X., 2015. The rural areas experiences conflicts under the urbanization process and its development issue. Chin. J. Environ. Manag. 7 (3), 57-62, 85. (in Chinese).

Shi, F., 2011. The transformation of residential patterns and influencing factors of henan rural residents. J. Henan Inst. Educ. (Philos. Soc. Sci). 30 (5), 85-88 (in Chinese).

Wang, Q.J., 2012. The Traditional Chinese Dwellings. China Electric Power Press, Beijing (in Chinese).

Wang, X.W., Zhou, J., 2011. The evolution of traditional village pattern: case study of Liang Village in Shanxi. Mod. Urban Res. 4, 30-36 (in Chinese).

Wang, Y.Q., Wang, L.L., Li, X.J., Zhang, H.Y., 2010. Strategy of spatial redistribution of 
ecological tourism development in abandoned mine land. Prog. Geogr. 29 (7), 811-817 (in Chinese).

Xu, D., 2009. Research on Sunk-yaodong's Conservation in Shanxian, Sanmenxia. Master Dissertation. Xi'an University of Architecture and Technology, Xi'an (in Chinese).

Yang, X.L., Chen, W.X., Yao, B.A., 2012. Pit furnace of vicissitudes. Chin. Local Style Dwell. Houses 4, 68-77 (in Chinese).

Yun, G.H., 2009. Shanxian County in Henan: the Main Source of China's Sunken Courtyard Culture. The Elephant Publishing House, Zhengzhou (in Chinese).

Zhang, X.J., 2011. The Research of Construction Technology about Pit House in
Western Henan Province from Ecology Perspective View: Example for the Pit House in Fan Village,Shan County,Sanmenxia City. Master Dissertation. Zhengzhou University, Zhengzhou (in Chinese).

Zhang, X.L., 1998. On discrimination of rural definitions. Acta Geogr. Sin. 53 (4), 365-371 (in Chinese).

Zhou, J., Zhong, X.H., 2015. Rural heritage preservation from the perspective of development: case study of DONG ethnic villages. Urban Plan. Forum 221 (1), 54-60 (in Chinese).

Zuo, M.C., Qu, T. Wang, F., 2012. The Traditional Dwellings in Henan. China Architecture and Building Press, Beijing (in Chinese). 